\title{
Neuropeptides as potential modulators of behavioral transitions in the ant Cataglyphis nodus
}

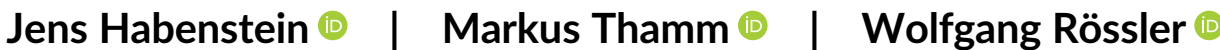

Behavioral Physiology and Sociobiology (Zoology II), Biocenter, University of Würzburg, Würzburg, Germany

\section{Correspondence}

Jens Habenstein and Wolfgang Rössler, Behavioral Physiology and Sociobiology (Zoology II), Biocenter, University of Würzburg, Am Hubland, 97074 Würzburg, Germany.

Email: jens.habenstein@uni-wuerzburg.de (J. H.) and roessler@biozentrum.uni-wuerzburg.de (W. R.)

Funding information

German Research Foundation (DFG), Grant/ Award Numbers: INST 93/829-1, DFG

Ro1177/7-1

\begin{abstract}
Age-related behavioral plasticity is a major prerequisite for the ecological success of insect societies. Although ecological aspects of behavioral flexibility have been targeted in many studies, the underlying intrinsic mechanisms controlling the diverse changes in behavior along the individual life history of social insects are not completely understood. Recently, the neuropeptides allatostatin-A, corazonin, and tachykinin have been associated with the regulation of behavioral transitions in social insects. Here, we investigated changes in brain localization and expression of these neuropeptides following major behavioral transitions in Cataglyphis nodus ants. Our immunohistochemical analyses in the brain revealed that the overall branching pattern of neurons immunoreactive (ir) for the three neuropeptides is largely independent of the behavioral stages. Numerous allatostatin-A- and tachykinin-ir neurons innervate primary sensory neuropils and high-order integration centers of the brain. In contrast, the number of corazonergic neurons is restricted to only four neurons per brain hemisphere with cell bodies located in the pars lateralis and axons extending to the medial protocerebrum and the retrocerebral complex. Most interestingly, the cell-body volumes of these neurons are significantly increased in foragers compared to freshly eclosed ants and interior workers. Quantification of mRNA expression levels revealed a stage-related change in the expression of allatostatin-A and corazonin mRNA in the brain. Given the presence of the neuropeptides in major control centers of the brain and the neurohemal organs, these mRNA-changes strongly suggest an important modulatory role of both neuropeptides in the behavioral maturation of Cataglyphis ants.
\end{abstract}

\section{KEYWORDS}

allatostatin-A, Cataglyphis, corazonin, division of labor, neuropeptides, social insects, tachykinin

\footnotetext{
Abbreviations: AL, antennal lobe; AMMC, antennal mechanosensory and motor center; Ast-A, allatostatin-A; CA, calyces; CANP, central adjoining neuropils; CB, central body; CBR, cell body rind; CO, collar; Crz, corazonin; CX, central complex; FLA, flange; INP, inferior neuropils; ir, immunoreactive; JH, juvenile hormone; KC, Kenyon cell; LA, lamina; LH, lateral horn; LO, lobula; ME, medulla; MB, mushroom body; NGS, normal goat serum; PBS, phosphate-buffered saline; PED, pedunculus; PER, proboscis extension reflex; PRW, prow; qPCR, quantitative real-time polymerase chain reaction; RCC, retrocerebral complex; SMP, superior medial protocerebrum; sNPF, short neuropeptide F; TK, tachykinin; TRP, tachykinin-related peptide; VG, vitellogenin; VL, vertical lobe; VLNP, ventrolateral neuropils; VMNP, ventromedial neuropils.
} 


\section{1 | INTRODUCTION}

Insect societies often comprise large numbers of individuals (Hölldobler \& Wilson, 1990; Wilson, 1971), and the organization within social-insect colonies is highly sophisticated and requires a species-specific and flexible task allocation. Some species exhibit distinct polymorphic worker castes devoted to specific tasks, for example, minor and major workers in leafcutting ants (Hughes et al., 2003; Wilson, 1980, 1984). However, most social insect species lack task-specific polymorphic worker castes. Instead, individual workers show a high degree of behavioral flexibility and different behavioral phenotypes are rather associated with the age (temporal polyethism) than with a specific morph (Hölldobler \& Wilson, 1990; Robinson, 1992; Robinson, 2002). Ants of the genus Cataglyphis (Foerster 1850) represent prominent examples for a marked temporal polyethism. Cataglyphis workers undergo distinct behavioral transitions. Newly emerged ants (callows), recognizable by their pale and soft cuticle, behave very sluggishly. Then, workers go through several interior phases inside the darkness of the nest. During the first 2 weeks, interior workers (interior I) serve as food storage for the colony (repletes) before they become more active (interior II) and accomplish tasks such as brood care or nest maintenance. The most drastic change, the interior-forager transition, happens after about 4 weeks when the ants leave the nest for the first time (Schmid-Hempel \& Schmid-Hempel, 1984; reviewed by Wehner \& Rössler, 2013). In order to calibrate their visual navigational systems, the ants first perform learning walks for 2-3 days close to the nest entrance before they finally start to forage solitarily (Fleischmann et al., 2017; Fleischmann et al., 2018; for reviews, see Grob et al., 2019; Rössler, 2019). The interior-forager transition is accompanied by fundamental changes in behavior. Whereas interior workers predominantly rely on olfactory and tactile cues inside the dark nest, foragers navigate on far-ranging foraging trips under bright sunlight mostly using visual compass cues (Ronacher, 2008; reviewed by Wehner \& Rössler, 2013; Buehlmann et al., 2014; Huber \& Knaden, 2015). The interior-forager transition is associated with high levels of structural synaptic plasticity in two visual pathways of the ants' brains (Grob et al., 2017; Schmitt et al., 2016; Stieb et al., 2010; Stieb et al., 2012). Recently, a detailed atlas of all brain neuropils and major connecting fiber systems in Cataglyphis nodus was published (Habenstein et al., 2020). This was complemented by a comprehensive peptidomic analysis of the $C$. nodus brain (Habenstein et al., 2021). Based on this profound knowledge on the behavioral transitions, brain anatomy, neuroplastic changes, and neuropeptide inventory, $C$. nodus ants are well-suited experimental models to address the potential role of neuropeptides in modulating intrinsic mechanisms underlying age-related behavioral plasticity.

Neuropeptides play crucial roles throughout an insect's life. They are involved in physiological and developmental processes and in the modulation of many essential behaviors (for reviews, see Fricker, 2012; Kastin, 2013; Nässel \& Zandawala, 2019). Recent studies suggest that the neuropeptides allatostatin-A (Ast-A), tachykinin (TK), and corazonin ( $\mathrm{Crz}$ ) act as regulators of behavioral plasticity in social insects (Gospocic et al., 2017; Han et al., 2021; Pratavieira et al., 2014; Schmitt et al., 2017; Takeuchi et al., 2003). Age-related fluctuations of Ast-A and/or TK have been revealed in honeybees
(Pratavieira et al., 2014; Takeuchi et al., 2003) and in the ant Cataglyphis fortis (Schmitt et al., 2017). Ast-A is a major regulator of the biosynthesis of juvenile hormone $(\mathrm{JH})$ in many insects (for reviews, see Weaver \& Audsley, 2009; Verlinden et al., 2015). However, a clear evidence for an allatoregulatory role is missing in Cataglyphis. In honeybees, Ast-A induces shifts in the stress reactivity and modulates appetitive olfactory memory (Urlacher et al., 2016; Urlacher et al., 2019). Ast-A as well as TK-related peptides (TRP) are suspected to further modulate aggressive behavior in bees (Pratavieira et al., 2018). TK signaling modulates locomotion and general activity levels (Kahsai et al., 2010; Winther et al., 2006), olfactory sensitivity (Gui et al., 2017; Jung et al., 2013; Ko et al., 2015; Winther et al., 2006), and nociception (Im et al., 2015). Although most of these studies were conducted in Drosophila, the similarities in the location of tachykinergic neurons in the antennal lobes (ALs) and the central complex (CX) may indicate similar functions in Cataglyphis (Habenstein et al., 2021; Schmitt et al., 2017). Whereas TK and Ast-A have been suggested to be involved in behavioral transitions in closely related $C$. fortis (Schmitt et al., 2017), Crz remained largely neglected in previous studies. $\mathrm{Crz}$ is a highly conserved neuropeptide and omnipresent in most insect species (Predel et al., 2007). In Drosophila, the endocrine corazonergic pathway is known to alter stress responses and metabolism (Johnson, 2017; Kapan et al., 2012; Kubrak et al., 2016; Zandawala et al., 2021). In addition, $\mathrm{Crz}$ signaling is important for the development of moth larvae (Kim et al., 2004; Tanaka, Hua, et al., 2002) and induces morphological changes in locusts, which are associated with behavioral transitions (Maeno et al., 2004; Sugahara et al., 2018; Tanaka, Zhu, et al., 2002; Tawfik et al., 1999). The effect of $\mathrm{Crz}$ on developmental processes is not restricted to insects, as similar effects of $\mathrm{Crz}$ on growth and maturation could be found in bristle worms (Andreatta et al., 2020). Gospocic et al. (2017) suggested that $\mathrm{Crz}$ is an important regulator of the sexual and behavioral differentiation in the ponerine ant Harpegnathos saltator. Higher $\mathrm{Crz}$ levels were found in workers compared to queens (or pseudoqueens). Moreover, worker-specific hunting behavior could be induced by experimental increase of $\mathrm{Crz}$ levels.

In the present study, we investigated the spatial expression patterns of Ast-A, TK, and Crz in callows, interior workers, and foragers of the ant C. nodus. We compared general innervation patterns and cell body volumes of peptidergic neurons across different behavioral stages using immunohistochemistry. In addition, we analyzed the mRNA levels of the three neuropeptides in the brain. The results show that expression levels and soma sizes particularly of Ast-A and Crz relate to the behavioral stage. This strongly suggests the involvement of these neuropeptides as modulators during behavioral maturation of Cataglyphis workers.

\section{2 | MATERIALS AND METHODS}

\section{$2.1 \mid$ Animals}

C. nodus nests were located in the Strofylia National Park, Greece $\left(38^{\circ} 15^{\prime} \mathrm{N}, 21^{\circ} 37^{\prime} \mathrm{E}\right)$. To be able to differentiate foragers from interior workers with high accuracy, foragers were marked outside the nest 
using acrylic paint (Motip Lackstift Acryl, MOTIP DUPLI GmbH, Haßmersheim, Germany) over at least three consecutive days before the nests were excavated. Afterward, all unmarked animals were considered to be either interior workers or callows. Callows were discriminated from interior workers by their pale cuticle. To ensure that callows and interior workers were never exposed to sunlight, the nest was excavated during night using red light. After excavation, the ants were kept in complete darkness in large plastic boxes with permanent access to water and honey water. Animals of different behavioral stages were collected arbitrarily out of the boxes and brains were dissected within $30 \mathrm{~h}$ after nest excavation. Dissections of the brains from ants of different behavioral stages were pseudo-randomized to avoid effects of potential daytime-dependent changes of neuropeptide expressions.

For the expression analyses, ant colonies were transferred to the University of Würzburg. In the laboratory, the ants were kept in a dark cabinet within a climate chamber at a constant temperature $\left(28^{\circ} \mathrm{C}\right)$ and relative humidity (30\%). The colonies had permanent access through a light trap connection into a foraging arena with a $12 \mathrm{~h} / 12 \mathrm{~h}$ day/night cycle. During the 12-h light cycle, light was generated by UV-emitting fluorescent tubes (Repti Glo 2.0/10.0, Exo Terra, Holm, Germany). In the foraging arena, the animals had an infinite supply of water and were fed with honey water (1:2) and dead arthropods twice a week. The animals were allowed to acclimate for $48 \mathrm{~h}$. Thereafter, all ants in the foraging arena were marked on three consecutive days and considered as foragers. In the following, all unmarked ants were classified as interior workers since no callows had remained in the colony after the transport to Würzburg.

\section{2 | Primary antibodies}

For immunolabeling, the following primary antibodies were used: antiAst-A (H. Agricola, Jena BioScience, Jena, Germany); anti-Crz (J.A. Veenstra, Université Bordeaux I, Bordeaux, France); anti-TK (LemTRP-1, D.R. Nässel, Stockholm University, Stockholm, Sweden); and anti-synapsin (SYN-ORF1, E. Buchner, University of Würzburg, Germany) (Table 1).
The polyclonal anti-Ast-A antibody was raised in rabbit and conjugated to thyroglobulin with glutaraldehyde. The specificity of the antiserum has been verified by a competitive enzyme-linked immunosorbent assay (ELISA) (Vitzthum et al., 1996) and its affinity was demonstrated in diverse insect species (e.g., Carlsson et al., 2013; Kahsai \& Winther, 2011; Kreissl et al., 2010) including Cataglyphis ants (Schmitt et al., 2017).

The polyclonal $\mathrm{Crz}$ antiserum was raised in rabbit and coupled to bovine serum albumin. The specificity of the antibody was characterized by ELISA (Veenstra, 1991; Veenstra \& Davis, 1993). The antibody was used to study the immunoreactivity to $\mathrm{Crz}$ in different arthropods (e.g., Hansen et al., 2001; Hou et al., 2017; Roller et al., 2003).

The polyclonal antibody to TK was raised in rabbit, conjugated to bovine serum albumin, and the specificity was characterized by preabsorbing with synthetic Leucophaea maderae TRP-1 (Winther \& Nässel, 2001). The antibody has been used for immunohistochemistry in various insects (e.g., Kahsai \& Winther, 2011; Neupert et al., 2012; Siju et al., 2014; Winther et al., 2003) including Cataglyphis (Habenstein et al., 2021; Schmitt et al., 2017).

To visualize synapse-rich neuropils, we used a monoclonal antibody to synapsin. The presence of synapsin in most synaptic terminals is highly conserved across invertebrate species (Hofbauer et al., 2009; Klagges et al., 1996). The antibody was raised in mice against fusion proteins of glutathione-S-transferase and Drosophila SYN1 protein (Klagges et al., 1996). The specificity has been verified in Drosophila (Godenschwege et al., 2004; Klagges et al., 1996) and in the honeybee Apis mellifera (Pasch et al., 2011). The antiserum was used for a variety of neuroanatomical studies in diverse arthropods (e.g., Groh \& Rössler, 2011; Heinze \& Reppert, 2012; Immonen et al., 2017; von Hadeln et al., 2018) including Cataglyphis ants (Habenstein et al., 2020; Schmitt et al., 2016; Schmitt et al., 2017; Stieb et al., 2012).

\section{3 | Immunohistochemistry}

Animals were anesthetized on ice and decapitated under red light. The head capsule was opened between the compound eyes and the

TABLE 1 Primary antibodies

\begin{tabular}{|c|c|c|c|}
\hline Antibody & Immunogen & Manufacturer; species; clonality; Cat \#; RRID & Dilution \\
\hline Allatostatin-A & APSGAQRLYGFGLa coupled to thyroglobulin & $\begin{array}{l}\text { H.J. Agricola, Jena BioScience, Jena, Germany; rabbit; } \\
\text { polyclonal; Cat \# Ast-A, RRID:AB_2313972 }\end{array}$ & $1: 2000$ \\
\hline Corazonin & pQTFQYSRGWTNa coupled to bovine serum albumin & $\begin{array}{l}\text { J.A. Veenstra, Université Bordeaux I, Bordeaux, France; } \\
\text { rabbit; polyclonal; Cat \# anti-corazonin, RRID: } \\
\text { AB_2532101 }\end{array}$ & $1: 1000$ \\
\hline Synapsin & $\begin{array}{l}\text { Drosophila Synapsin glutathione-S-transferase fusion } \\
\text { protein }\end{array}$ & $\begin{array}{l}\text { E. Buchner, Theodor-Boveri-Institute, University of } \\
\text { Würzburg, Germany; mouse; monoclonal; Cat \# } \\
\text { 3C11 (SYNORF1); RRID: AB_528479 }\end{array}$ & $1: 50$ \\
\hline Tachykinin & APSGFLGVRa coupled to bovine serum albumin & $\begin{array}{l}\text { D.R. Nässel, Stockholm University; Stockholm; } \\
\text { Sweden; rabbit; polyclonal; Cat \# LemTRP-1, RRID: } \\
\text { AB_2315469 }\end{array}$ & $1: 2500$ \\
\hline
\end{tabular}


brain was covered with ice-cold physiological ant saline (126.6 mM $\mathrm{NaCl}, 6.7 \mathrm{mM} \mathrm{KCl}, 1.5 \mathrm{mM} \mathrm{CaCl}, 0.8 \mathrm{mM} \mathrm{Na} \mathrm{HPO}_{4}, 0.4 \mathrm{mM}$ $\mathrm{KH}_{2} \mathrm{PO}_{4}, 4.8 \mathrm{mM}$ TES, and $3.2 \mathrm{mM}$ trehalose; $\mathrm{pH}$ 7.0). The brains were removed and fixated in $4 \%$ formaldehyde in phosphate-buffered saline (PBS) overnight at $4^{\circ} \mathrm{C}$. Thereafter, the brains were rinsed in PBS $\left(3 \times 10 \mathrm{~min}\right.$ ), stored in PBS in the dark at $4^{\circ} \mathrm{C}$ for up to 3 days, and subsequently transferred in a cooler to Würzburg. In Würzburg, samples were stored at $4^{\circ} \mathrm{C}$ until further processing for up to two more days. To facilitate the penetration of the antibodies, the brains were treated with PBS containing Triton-X (PBST; 2\% PBST for $10 \mathrm{~min}, 0.5 \%$ PBST for $3 \times 10 \mathrm{~min}$ ). Subsequently, the brains were preincubated in $0.5 \%$ PBST with $2 \%$ normal goat serum (NGS) for $1 \mathrm{~h}$ at $4{ }^{\circ} \mathrm{C}$ before the brains were incubated in the primary antibody solution (2\% NGS in $0.5 \%$ PBST, either Ast-A, Crz or TK, dilution see Table 1$)$ for 4 days at $4^{\circ} \mathrm{C}$. After rinsing in PBS $(3 \times 10 \mathrm{~min})$, the brains were transferred into the anti-synapsin antibody solution ( $2 \%$ NGS in $0.2 \%$ PBST, Table 1) to incubate for another 4 days at $4^{\circ} \mathrm{C}$. Thereafter, brains were again rinsed in PBS $(3 \times 10 \mathrm{~min})$ followed by incubation in the secondary antibodies Alexa Fluor 488 goat anti-rabbit (1:250; RRID: AB_143165, Thermo Fisher Scientific, Waltham, MA) and CF633 goat anti mouse (1:250; Biotrend Chemikalien GmbH, Köln, Germany) in PBS containing $1 \%$ NGS for 3 days at $4^{\circ} \mathrm{C}$. Brains were washed in PBS ( $3 \times 10 \mathrm{~min}$ ), dehydrated through an ascending ethanol series (30, 50, $70,90,95,100$, and $100 \%$ for 10 min each step) and finally cleared in methyl salicylate (M-2047; Sigma Aldrich, Steinheim, Germany).

\subsection{Laser scanning confocal microscopy, image processing, and data analysis}

Imaging of the brain samples was performed with a confocal laser scanning microscope (Leica TCS SP8, Leica Microsystems AG, Wetzlar, Germany). For scans of the whole brain, we used a $20 \times$ glycerol immersion objective (Leica HC PL APO $20.0 \times 0.75$ NA) with a step size of $5 \mu \mathrm{m}$ in z-direction. For detailed scans of individual brain regions or neurons, we used a $63 \times$ glycerol immersion objective (Leica HCX PL APO $63.0 \times 1.3 \mathrm{NA}$ ) with a step size of $1 \mu \mathrm{m}$ in $z$-direction. All image stacks were scanned at a resolution of $1024 \times 1024$ pixels and processed using ImageJ (ImageJ 1.52p; Wayne Rasband, $\mathrm{NIH}$, Bethesda, MD) and CorelDRAW X8 (Version 20.0.0.633, Corel Corporation, Ottawa, Canada). To improve the quality of images, contrasts were adjusted in ImageJ if necessary. For volume calculations of $\mathrm{Crz}$ positive cell bodies, image stacks were analyzed using the software Amira 2019.1 (FEI, Visualization Sciences Group, Hillsboro, OR; http://thermofisher.com/amira-avizo). The step size of the z-axis was corrected according to deviations caused by the immersion medium (1.05 for glycerol). The cell bodies of interest were manually labeled in each layer of the image stack. Thereafter, the three-dimensional structure was reconstructed, and the volume was measured applying the respective tools of the Amira software. To compare the volumes of the corazonergic somata between different brains, we averaged the volume of all corazonergic cell bodies of each brain hemisphere. In some cases ( 8 out of 65 brains), the cell bodies of one hemisphere were damaged or the quality of confocal images was not sufficient for analyzing the volumes. In those cases, we used only the volume of the corazonergic somata of one hemisphere.

\section{5 | RNA extraction and cDNA synthesis}

- Preparation in Greece: Ants were chosen arbitrarily from the colony according to their behavioral stage. Then, ants were anesthetized on ice, the head was removed, and a small window was cut into the head capsule to allow the penetration of RNAlater stabilization solution (Thermo Fisher Scientific) into the brain tissue. The samples were stored in the RNAlater solution in the dark at $4^{\circ} \mathrm{C}$ for up to 3 days before they were transferred in a cooler to Germany.

- Preparation in the laboratory: Ants were collected arbitrarily from the colony according to their behavioral stage and immediately snap-frozen in liquid nitrogen. Samples were stored in a freezer at $-80^{\circ} \mathrm{C}$ until the brain was dissected.

All brains were dissected in RNAlater solution, transferred into a reaction tube and snap-frozen in liquid nitrogen. Samples were stored at $-80^{\circ} \mathrm{C}$ until RNA extraction. For RNA extraction, the brains were homogenized in $750 \mu$ l TriFast (peqGOLD, VWR, Radnor, PA) with the Tissuelyzer LT (QIAGEN, Venlo, Netherlands) at $40 \mathrm{~Hz}$ for $3 \mathrm{~min}$ using stainless steel beads ( $5 \mathrm{~mm}$ ). After $5 \mathrm{~min}$ incubation, $150 \mu \mathrm{l}$ chloroform was added and mixed with the solution. Subsequently, the samples were centrifuged, and the aqueous phase was transferred in a perfectBind RNA column (peqGOLD total RNA Kit, VWR). Further RNA extraction was carried out according to the manufacturer instructions of the peqGOLD total RNA kit. RNA was resolved in $\mathrm{H}_{2} \mathrm{O}$ and precipitated with $4 \mathrm{M}$ lithium chloride and ethanol at $4{ }^{\circ} \mathrm{C}$ overnight. After centrifugation, the RNA pellet was washed with ethanol and dissolved in $\mathrm{H}_{2} \mathrm{O}$ adjusted to the respective RNA concentration.

Synthesis of the cDNA was performed using the QuantiTect Reverse Transcription Kit (QIAGEN). About 500 ng of the RNA (in $8 \mu \mathrm{l}$ $\mathrm{H}_{2} \mathrm{O}$ ) were mixed with the buffer solution ( $2 \mu \mathrm{l}$ gDNA wipeout buffer in $4 \mu \mathrm{l} \mathrm{H}_{2} \mathrm{O}$ ) and preincubated for $2 \mathrm{~min}$ at $42^{\circ} \mathrm{C}$. Thereafter, $1 \mu \mathrm{l}$ Quantiscript reverse transcriptase (RT), $4 \mu$ l Quantiscript RT buffer, and $1 \mu \mathrm{l}$ RT primer mix were added and the solution was incubated at $42^{\circ} \mathrm{C}$ for $15 \mathrm{~min}$ before the reaction was terminated at $95^{\circ} \mathrm{C}$ for $3 \mathrm{~min}$. The cDNA solution was cooled at $4^{\circ} \mathrm{C}$ and $30 \mu \mathrm{l} \mathrm{H}_{2} \mathrm{O}$ was added before the samples were stored at $-20^{\circ} \mathrm{C}$ until usage.

\subsection{Quantitative real-time polymerase chain reaction}

Quantitative real-time polymerase chain reaction (qPCR) analysis was performed using Rotor Gene Q (Qiagen, Hilden, Germany). Genes of interest and the reference gene were analyzed in duplex runs. Primer and TaqMan probes (TIB MOLBIOL, Berlin, Germany) used for qPCR are listed in Table 2. Each individual sample was analyzed in triplicates. Each reaction contains $5 \mu \mathrm{l}$ cDNA, $10 \mu$ Biozym Blue Probe qPCR Mix 
(Biozym Scientific GmbH, Hessisch Oldendorf, Germany), $0.4 \mu \mathrm{l}$ of each primer (each $20 \mu \mathrm{M}$ ) and TaqMan probe (each $10 \mu \mathrm{M}$ ), and $2.4 \mu \mathrm{l}$ water. Initial denaturation was performed at $95^{\circ} \mathrm{C}$ for $2 \mathrm{~min}$. Thereafter, 40 cycles including denaturation $\left(95^{\circ} \mathrm{C}\right.$ for $\left.5 \mathrm{~s}\right)$ and annealing/extension $\left(60^{\circ} \mathrm{C}\right.$ for $\left.30 \mathrm{~s}\right)$ phases were carried out. Neuropeptide expression levels were determined relative to transcripts of elongation factor-1 alpha (EF1 $\alpha)$ using the $\Delta \Delta \mathrm{Ct}$ method. EF1 $\alpha$ was shown to be a suitable reference gene in brains of honeybees (Lourenço et al., 2008; Reim et al., 2013) and several ant species (Moreira et al., 2017; Ratzka et al., 2011). Therefore, we decided to use this gene in $C$. nodus. We calculated and compared the absolute copy number of EF1a. Here, we observed no differences ( $p_{\text {Greece }}=0.59, \chi^{2}=1.056$, Kruskal-Wallis test; $p_{\text {lab }}=0.432$, $Z=0.893, U=23.00$, Mann-Whitney $U$ test) in all data sets and thus, defined this gene as stable.

\section{7 | Statistical analyses}

Statistical analyses were performed using SPSS statistic software package (IBM Corp.; IBM SPSS Statistics for Windows, Version 25.0.0.1, Armonk, NY). Normality was tested using the Shapiro-Wilk-test. As not all data sets were normally distributed, we used nonparametric tests for all statistical analyses. Data sets with more than two groups were tested by using the Kruskal-Wallis test $(\alpha=.05)$. To analyze significant differences between the groups, post hoc pairwise comparisons were performed using the Mann-Whitney $U$ test with Bonferroni correction. For all data sets with two behavioral groups, we used the Mann-Whitney $U$ test $(\alpha=.05)$.

\section{8 | Nomenclature}

We followed the unified nomenclature rules for insect brains (Ito et al., 2014). To identify neuropils of the central brain, we used the three-dimensional atlas of the $C$. nodus brain as a reference (Habenstein et al., 2020) (see also https://www.insectbraindb.org to access 3D reconstructions of the $C$. nodus brain).

\section{3 | RESULTS}

\subsection{Ast-A, Crz, and TK immunoreactivity in Cataglyphis workers}

To compare the localization of neuropeptides in Cataglyphis brains across different behavioral stages, we used immunohistological stainings with antibodies specific for Ast-A, Crz, and TK. Close visual inspection did not reveal any obvious differences in the general distribution and branching patterns of Ast-A-, Crz-, and TK-like immunoreactivity (Ast-A-ir, Crz-ir, and TK-ir) among callows, interior workers, and foragers. Across all three behavioral stages, Ast-A-ir is localized in numerous neurons of the brain with arborizations in important primary sensory neuropils such as the $A L$ and the optic lobes (OL, Figure $1(a, f)$ ). We found Ast-A-ir scattered across the entire volumes of virtually all $A L$ glomeruli (Figure $1(a, d)$ ). In the lobula (LO) and medulla (ME), Ast-A-ir neurons are only present in very distinct neuropil layers. In contrast, branches of Ast-A-ir neurons were found across the entire lamina neuropil (Figure 1(f)). Ast-A-ir is also present in prominent high-order integration centers of the brain (Figure $1(a-c, e)$ ). Ast-A-ir neurons innervate the central body (CB), but not the protocerebral bridge and the noduli. Ast-A-ir was present in different subunits of the mushroom body (MB) such as the pedunculus (PED), the collar (CO), and a subset of extrinsic MB neurons of the vertical lobe (VL, Figure $1(a-c, e))$. The neurons arborizing in the $V L$ project into the protocerebral-calycal tract (PCT, Figure 1(b)). In honeybees, the neurons of the PCT provide GABAergic feedback to the MB calyces (Grünewald, 1999; Haehnel \& Menzel, 2010). Our staining revealed AstA-ir neurons also beyond the major neuropils in brain regions with less

TAB LE 2 Oligonucleotides used for quantitative real-time PCR

\begin{tabular}{|c|c|c|c|}
\hline Name & Direction & Sequence & Concentration $(\mu \mathrm{M})$ \\
\hline \multirow[t]{2}{*}{ Allatostatin-A } & Sense & 5'-TTCCCTATGCCGAACCTGTA-3' & 20 \\
\hline & Antisense & 5'-ATAGCGAGGATAAACGGACG-3' & 20 \\
\hline \multirow[t]{2}{*}{ Corazonin } & Sense & 5'-AACGGTGATCTCAACAGACTGAA-3' & 20 \\
\hline & Antisense & 5'-GGATTATCAGCGGTTGTTCGTC-3' & 20 \\
\hline \multirow[t]{3}{*}{ Elongation factor-1 alpha } & Sense & 5'-CCAGGACAGATCAGCAACG-3' & 20 \\
\hline & Antisense & 5'-TCCTTAATCTCGGCGAACTTG-3' & 20 \\
\hline & TM & 5'-6FAM-ACCGGTTCTCGATTGCCATACCG-BBQ-3' & 10 \\
\hline \multirow[t]{2}{*}{ Tachykinin } & Sense & 5'-GGTACTCGCGGCAAGTTGAA-3' & 20 \\
\hline & Antisense & 5'-ССТCTCATGCCCTGAAAACC-3' & 20 \\
\hline
\end{tabular}

Abbreviation: PCR, polymerase chain reaction. 

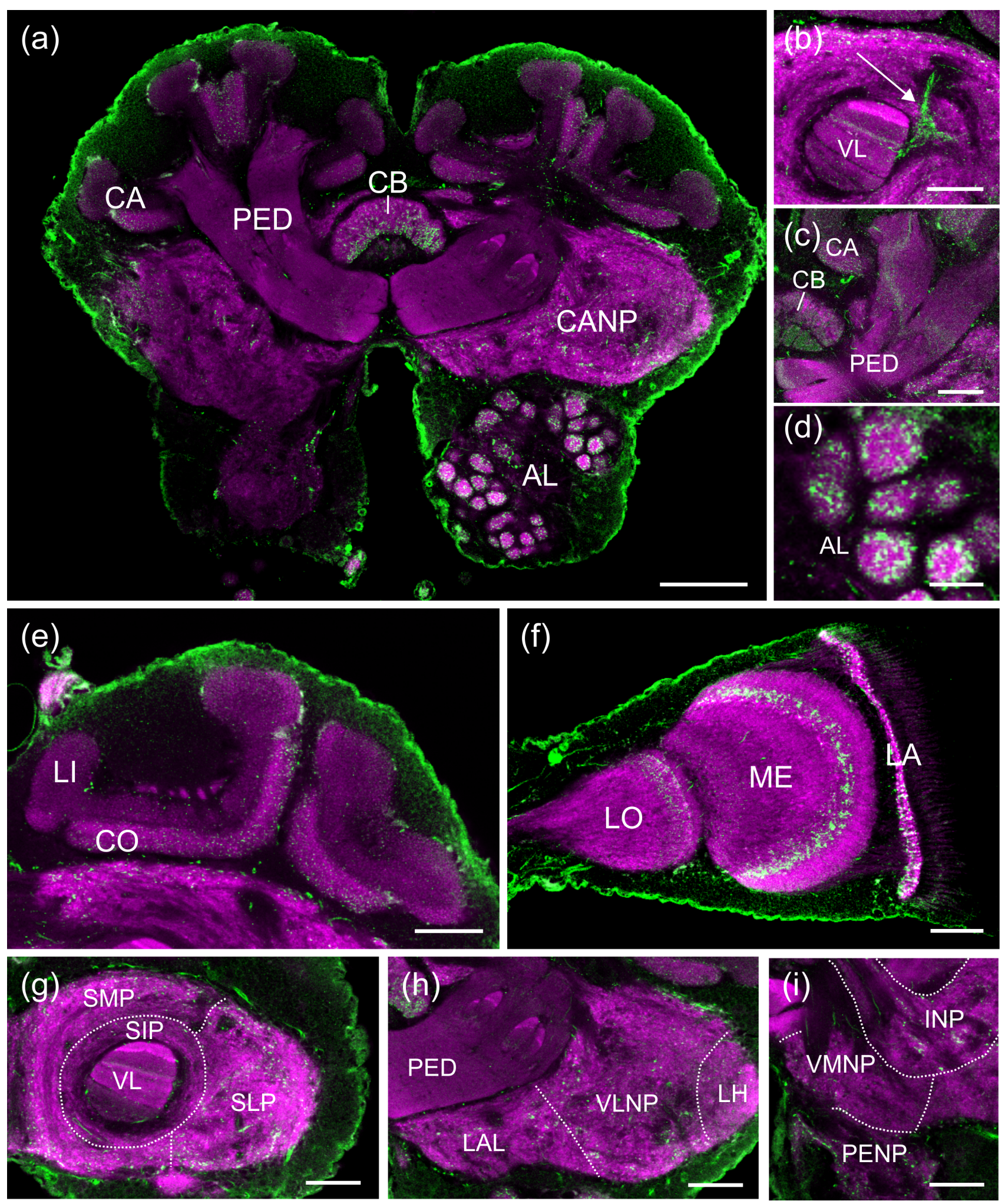

FIGURE 1 Immunofluorescence staining of allatostatin-A (Ast-A; green) and synapsin (magenta) in Cataglyphis nodus brain. (a) Overview of Ast-A-immunoreactivity (-ir) in the central brain. Ast-A-ir neurons are present in the central body (CB), the collar (CO) of the mushroom body calyx (CA), the antennal lobes ( $A L$ ), and across the central adjoining neuropils (CANP). (b) The vertical lobe (VL) is innervated by a layer of Ast-A positive neurons. Ast-A-ir neurons connect the $\mathrm{VL}$ with the $\mathrm{CA}$ by the protocerebral-calycal tract (white arrow; z-projection from a stack of four optical sections, $5 \mu \mathrm{m}$ step size). (c) Pattern of Ast-A-ir in the pedunculus (PED). (d) Higher magnification image of the Ast-A-ir distribution in the AL glomeruli. (e) Ast-A-ir in the CA. Ast-A innervation of the CA was restricted to the visual CO and absent in the lip (LI). (f) Overview of Ast-A-ir in the optic lobes. Lobula (LO), medulla (ME), and lamina (LA) are innervated by a layer of Ast-A-ir neurites. (g-i) Ast-A-ir in the CANP. (g) Ast-A-ir is present in all superior neuropils which consist of superior lateral protocerebrum (SLP), the superior intermediate protocerebrum (SIP), and the superior medial protocerebrum (SMP). (h) Pattern of Ast-A-ir in the lateral accessory lobe (LAL), the ventrolateral neuropils (VLNP), and the lateral horn (LH). (i) Ast-A-ir in the inferior neuropils (INP), the periesophageal neuropils (PENP), and the ventromedial neuropils (VMNP). Scale bars $=100 \mu \mathrm{m}(\mathrm{a}) ; 50 \mu \mathrm{m}(\mathrm{b}, \mathrm{c}, \mathrm{e}-\mathrm{i}) ;$ and $20 \mu \mathrm{m}(\mathrm{d})$ 
distinct boundaries, known as central adjoining neuropils (CANP) (Habenstein et al., 2020). Our detailed brain atlas (Habenstein et al., 2020) enabled us to assign branching patterns to neuropils within central brain regions that have not been accessible in a previous study on Ast-A neurons in the closely related ant C. fortis (Schmitt et al., 2017). In particular, Ast-A-ir is present in the lateral accessory lobe, the superior neuropils (SNP), the inferior neuropils, the ventrolateral neuropils (VLNP), the lateral horn (LH), and less pronounced also in more posterior neuropils, such as in the ventromedial neuropils (VMNP) and the periesophageal neuropils (Figure 1(a,g-i)). We found no Ast-A-ir in the antennal mechanosensory and motor center (AMMC). Numerous cell bodies of the Ast-A-ir neurons are dispersed across the entire cell body rind (CBR). The distribution of TK-ir neurons did not reveal any obvious differences between the three behavioral stages. Similar to the Ast-A-ir, innervation by numerous TK-ir neurons was present in major sensory input regions, high-order processing centers and extensively in the CANP (Figure 2). We found very dense TK-ir across the entire volume of virtually all AL glomeruli (Figure 2(a,c)). In the ME and LO, TK-ir is present only in distinct layers. However, in contrast to the Ast-A-ir pattern, we found no TK-ir in the LA (Figure 2(d)). Similar to the pattern found in AstA-ir neurons in the CX, TK-ir is restricted to the CB and absent in the protocerebral bridge and noduli. The PED is intensely innervated by TKir neurons, which is reflected in labeling of multiple layers in the MB VL (Figure 2(a,b)). TK-ir was found in very prominent ventral and several distinct dorsal layers of the VL (Figure $2(b, f)$ ). In the honeybee, the ventralmost layer is known as the gamma lobe receiving input from Type II (clawed) Kenyon cells (KCs) and more dorsal layers include terminal branching areas of Type I (spiny) KCs with dendritic arborizations in visual and olfactory parts of the MB calyx (Strausfeld, 2002). By contrast, Ast-A-ir neurons are not present in the gamma lobe and innervate only a single dorsal layer of the VL (Figure 1(b)). As we did not find any Ast-Aand $\mathrm{TK}$-ir in $\mathrm{KC}$ cell bodies, we assume that all labeling within the MB neuropil is from MB extrinsic neurons. Another difference of both neuropeptide distributions was visible in posterior CANPs. We found more arborizations of TK-ir neurons in these regions including dense innervation of the AMMC (Figure 2(e)). Similar to Ast-A, numerous TK-ir cell bodies distribute all across the entire CBR. A particularly prominent cluster of TK positive cell bodies is present in the lateral cluster of AL neurons (Figure 2(c)).

In contrast to the labeling of Ast-A and TK, Crz-ir neurons show very different and distinct branching patterns. They are restricted to a very small number of neurons forming a tight cluster in each brain hemisphere. Each cluster consists of four cell bodies, located in the pars lateralis (Figure 3(a,d)), a region housing neurosecretory cells in insects (Veelaert et al., 1998; Siegmund \& Korge, 2001; reviewed by Raabe, 2012). The Crz-ir neurons extend projections into the superior medial protocerebrum (SMP) and the flange (FLA, Figure $3(a-c))$. In addition, one axon bundle per hemisphere projects into the ipsilateral retrocerebral complex (RCC, Figure 3(c,e,f)), a major neurohemal organ in insects (Gade et al., 1997; Predel, 2001). The rest of the central brain, including sensory input regions and high-order processing and integration sites, did not show any Crz-ir. Like the other two neuropeptides, $\mathrm{Crz}$-ir neurons did not exhibit obvious differences in their branching patterns between callows, interior workers, and foragers.

Despite consistent general branching patterns of Ast-A-, TK-, and $\mathrm{Crz}$-ir neurons in ants of different behavioral stages, we analyzed potential differences in the volume of cell bodies. This was possible in the case of $\mathrm{Crz}$-ir neurons due to the relatively large size of the cell bodies and their small overall number. We reconstructed the three-dimensional structure of the four $\mathrm{Crz}$-ir somata in callows, interior workers, and foragers to compare their volumes. Foragers displayed significantly larger $\mathrm{Crz}$-ir somata than callows ( $\left.p<.001, Z=4.424, \chi^{2}=20.345\right)$ and interior workers ( $p<.001, Z=4.422, \chi^{2}=19.417$, Figure 4). To exclude seasonal or colony related factors, the experiment was repeated for interior workers and foragers from another $C$. nodus colony at a different time of the year (June instead of August). Likewise, corazonergic cell-body volumes were significantly ( $p<.001, Z=3.971, U=151.0)$ larger in foragers (mean volume $9.22 \pm 2.28 \times 10^{3} \mu \mathrm{m}, n=13$ ) compared to interior workers (mean volume $=4.97 \pm 1.11 \times 10^{3} \mu \mathrm{m}, n=12$, data not shown).

\section{2 | Quantitative real-time PCR comparison of neuropeptide mRNA expression}

To investigate potential differences at the level of gene expression, we compared the mRNA expression levels of TK, Ast-A, and $\mathrm{Crz}$ in ants of the three behavioral stages. To measure mRNA levels as close to the natural conditions as possible, we conducted the experiments on ants collected in their natural habitat within the Strofylia National Park (Greece). This revealed neuropeptide-specific differences between mRNA expression levels in the three behavioral stages (Figure 5). Ast-A mRNA expression was significantly lower in interior workers compared to both callows $(p=.047$, $\left.Z=2.414, \chi^{2}=11.00\right)$ and foragers $\left(p=.005, Z=3.12, \chi^{2}=12.542\right.$, Figure $5(\mathrm{a}))$. In contrast, TK mRNA expression levels remained stable throughout the different behavioral stages ( $p=.788, \chi^{2}=0.477$, Figure 5 (b)). The largest change in relative mRNA expression levels was found for $\mathrm{Crz}$ with more or less similar expression levels in callows and interior workers ( $p=1.00, Z=0.864, \chi^{2}=3.938$ ), but a significant increase in foragers compared to callows ( $p=.002, Z=3.433, \chi^{2}=16.50$ ) and interior workers ( $p=.005, Z=3.124, \chi^{2}=12.562$ ). Interestingly, the median of the relative expression value for $\mathrm{Crz}$ in foragers is almost twice as high as in the other behavioral stages (Figure 5(c)).

To minimize artificially generated errors (e.g., changed mRNA production caused by stress during excavation of the nest), we repeated the experiment using the same colony after it was transferred to constant conditions in our climate chamber in Würzburg. Since no more callows were present in the colony after this transition, only interior workers and foragers were used for this part of the expression analysis. The analyses confirmed all results from the measurements under natural colony conditions. Foragers and interior workers displayed similar TK expression levels ( $p=.876, Z=0.244, U=19.00)$. In contrast, both $\mathrm{Crz}(p=.018$, $Z=2.355, U=32.00)$ and Ast-A $(p=.018, Z=2.355, U=3.00)$ expression was significantly higher in foragers compared to interior workers with $\mathrm{Crz}$ showing the highest difference in expression levels (Figure 6). 

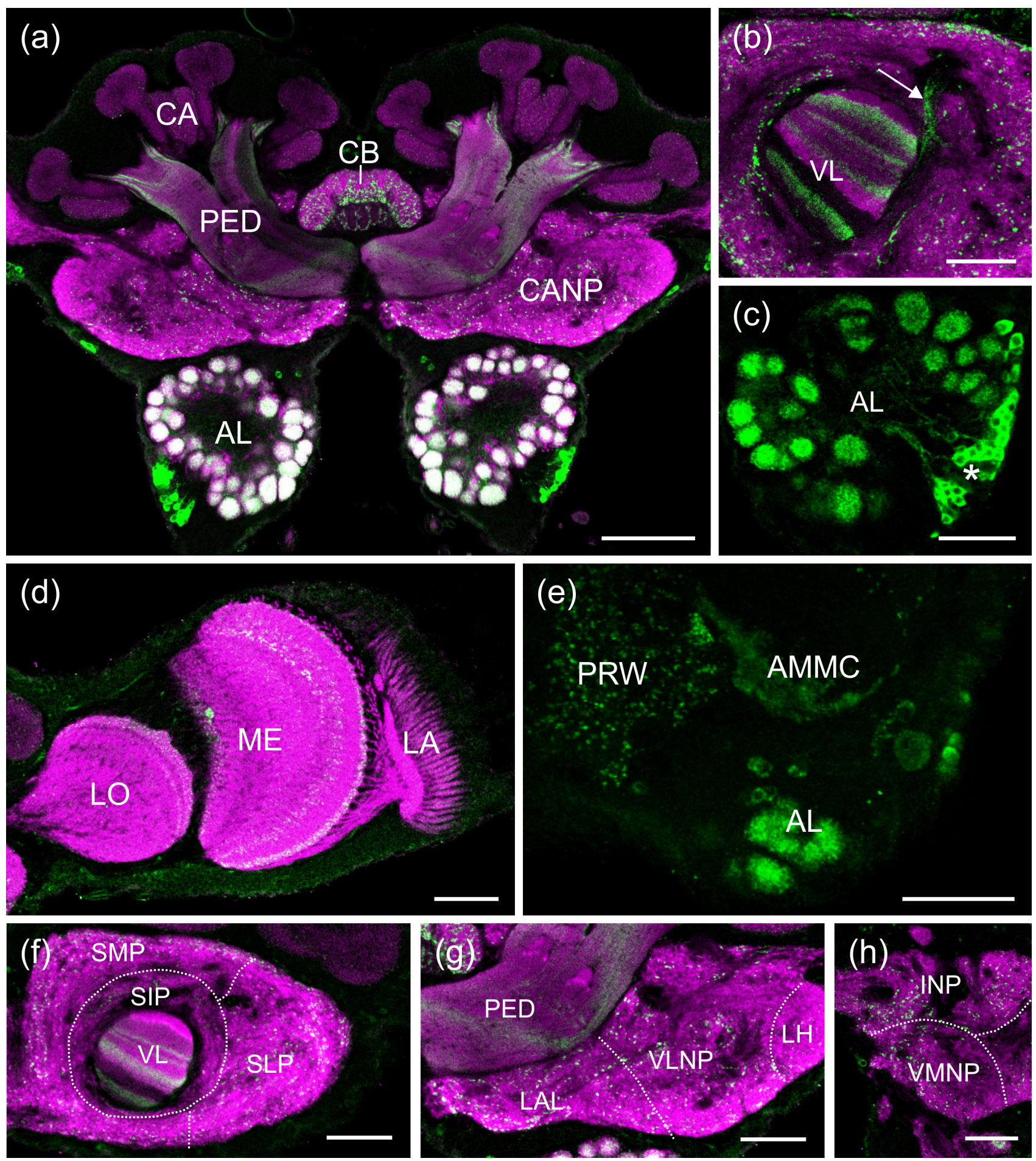

FIGURE 2 Immunofluorescence staining of tachykinin (TK; green) and synapsin (magenta) in the Cataglyphis brain. (a) Overview of TKimmunoreactivity (-ir) in the central brain. Innervation of TK-ir neurons was found in the upper and lower unit of the central body (CB), the pedunculus (PED), the antennal lobes (AL), and the central adjoining neuropils (CANP). (b) TK-ir neurons innervate several layers of the vertical lobe $(\mathrm{VL})$ and project into the protocerebral-calycal tract (white arrow). (c) Dense pattern of TK-ir throughout AL glomeruli. Numerous TK-ir cell bodies (asterisk) in the lateral cluster of AL neurons project into all glomeruli of the AL. (d) TK-ir in the lobula (LO) and medulla (ME) of the optic lobes. No staining was found in the lamina (LA). (e-h) TK-ir in the CANP. (e) TK-ir in the periesophageal neuropils (z-projection of six optical sections, $5 \mu \mathrm{m}$ step size). TK-ir was found in the antennal mechanosensory and motor center (AMMC) and the prow (PRW). ( $\mathrm{f}$ ) TK is present in all superior neuropils (SNP) and the VL. The SNP comprise the superior lateral protocerebrum (SLP), the superior intermediate protocerebrum (SIP), and the superior medial protocerebrum (SMP). (g) TK-ir is present in the in the lateral accessory lobe (LAL), the ventrolateral neuropils (VLNP), and the lateral horn (LH). (h) TK-ir neurons innervate the inferior neuropils (INP) and the ventromedial neuropils (VMNP). Scale bars $=100 \mu \mathrm{m}(\mathrm{a})$ and $50 \mu \mathrm{m}$ (b-h). CO, collar 


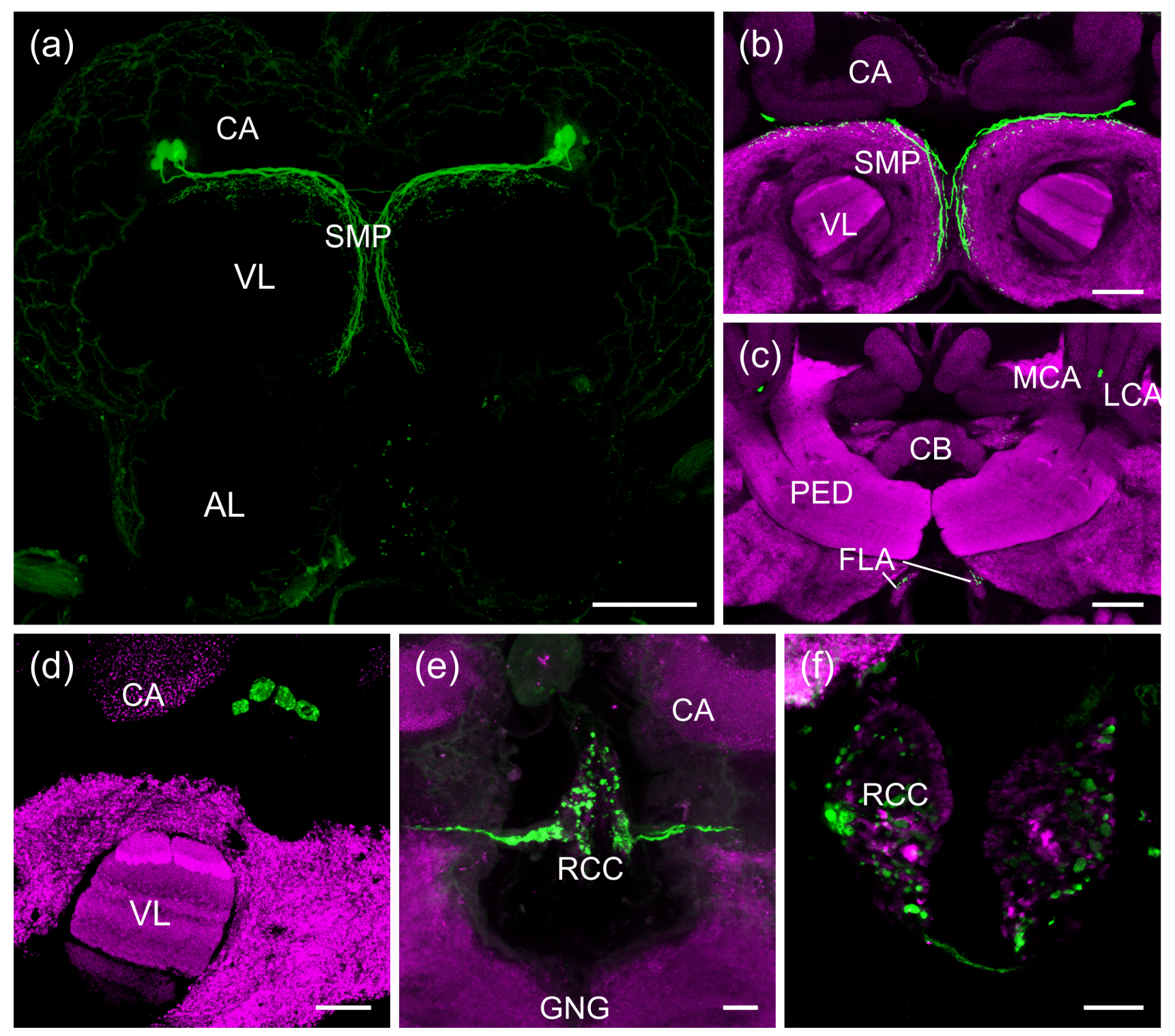

FIG URE 3 Corazonin-immunoreactivity (Crz-ir, green) in the brain of Cataglyphis nodus. Anti-synapsin (magenta) highlights synapse-rich brain neuropils. (a) $\mathrm{Crz}$-ir in the anterior part of the central brain (z-projection of 18 optical sections, step size $5 \mu \mathrm{m}$ ). Each brain hemisphere contains a cluster of four corazonergic somata in the region of the pars lateralis. Crz-ir neurons project into the medial protocerebrum. (b) Innervation pattern of $\mathrm{Crz}$-ir neurons in the superior medial protocerebrum (SMP). (c) Crz-ir neurons project into the flange (FLA). One neuron bundle per hemisphere runs in between the medial (MCA) and lateral calyx (LCA) of the mushroom bodies to posterior brain regions ( $z$-projection from 3 optical sections, $5 \mu \mathrm{m}$ step size). (d) Typical cluster of the total of four somata in the region of the pars lateralis (z-projection of three optical sections, $2 \mu \mathrm{m}$ step size). (e) Crz-ir neurons leave the posterior brain and project into the retrocerebral complex (RCC) ( $z$-projection of 22 optical images, $1 \mu \mathrm{m}$ step size). (f) Pattern of Crz-ir in the RCC. Scale bars $=100 \mu \mathrm{m}$ (a); $50 \mu \mathrm{m}$ (b,c); and $25 \mu \mathrm{m}$ (d-f). AL, antennal lobes; CB, central body; GNG, gnathal ganglion; PED, pedunculus; VL, vertical lobe

\section{4 | DISCUSSION}

\subsection{Distribution of Ast-A, TK, and Crz in the Cataglyphis brain}

Ast-A and TK belong to the most abundant neuropeptides in the Cataglyphis brain. Both have multiple paracopies within the respective prepropeptide (Habenstein et al., 2021) and, as shown in our present work, extensively innervate major portions of the ant's brain, with differences in individual neuropils as described in the results section. They are present in high-order processing centers as well as in major visual, antennal mechanosensory, and olfactory neuropils (Figures 1 and 2) which is in line with previous studies in the closely related ant C. fortis (Schmitt et al., 2017) and with data from mass spectrometric analyses in C. nodus (Habenstein et al., 2021). Both TK- and Ast-A-ir neurons innervate the $C B$ of the $C X$. The $C X$ is implicated in processing sky-polarization information in various insects (reviewed by Homberg et al., 2011; el Jundi et al., 2014) and plays a role in path 

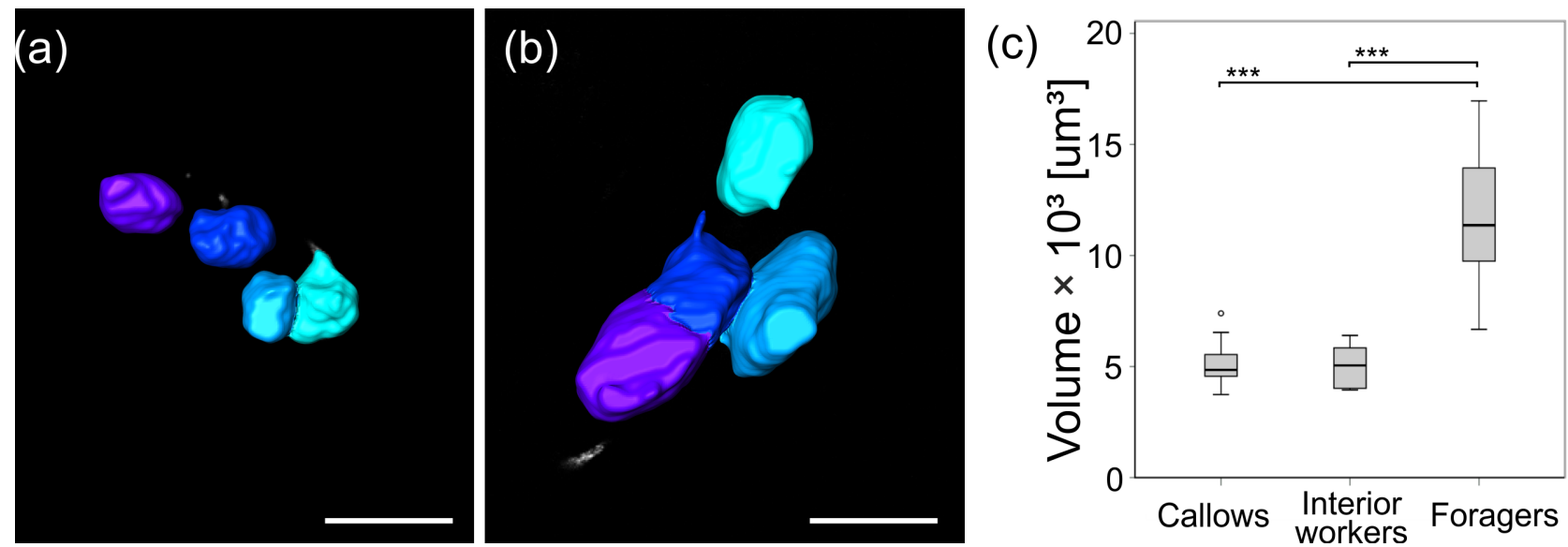

FIGURE 4 Volumes of corazonergic somata increase during behavioral maturation of Cataglyphis ants. Colors of individual cell bodies were assigned randomly in (a) and (b). (a) Example of a three-dimensional reconstruction of the corazonin-immunoreactive (Crz-ir) cell bodies of one brain hemisphere of an interior worker. (b) Example of a three-dimensional reconstruction of $\mathrm{Crz}$-ir cell bodies of one brain hemisphere of a forager. (c) Volume changes of corazonergic cell bodies in the pars lateralis of callows $(n=14)$, interior workers $(n=14)$, and foragers $(n=12)$. The average volume of the somata is significantly increased in foragers. In c), volumes have been calculated from the four corazonergic cell bodies per hemisphere. Volumes of cell bodies in the two brain hemispheres were averaged. Boxes indicate 25th and 75th percentiles and the solid line represents the median of the data. Whiskers extend to all data points within 1.5 times of the interquartile length from the median. Outliers are shown as circle. For statistics, Kruskal-Wallis test with Bonferroni correction was used. Significant different data are indicated by an asterisk $(\alpha=.05)$. Scale bars $=20 \mu \mathrm{m}$ [Color figure can be viewed at wileyonlinelibrary.com]

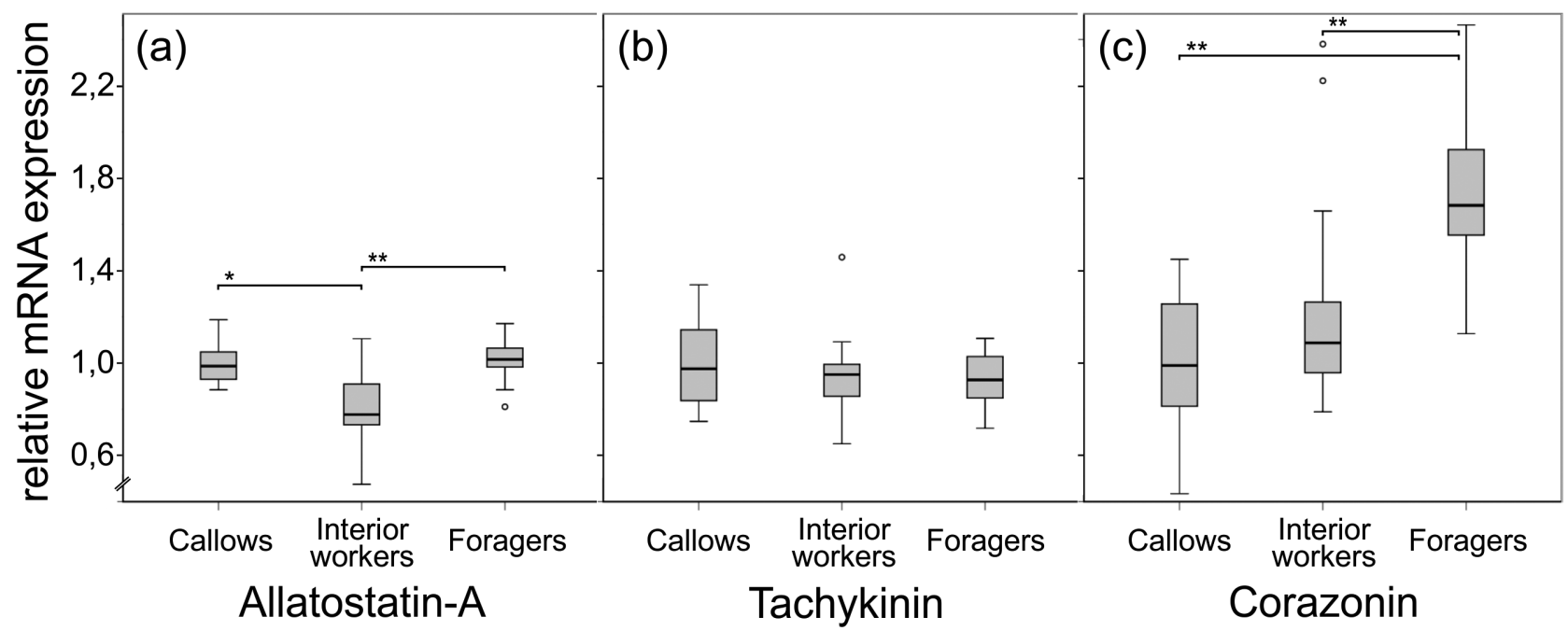

FIGURE 5 Changes of allatostatin-A (Ast-A), tachykinin (TK), and corazonin (Crz) expression in brains of ants at different behavioral stages (field study). (a) Ast-A expression in callows $(n=8)$, interior workers $(n=16)$, and foragers $(n=12)$. Ast-A expression is significantly lower in interior workers. (b) TK expression in callows $(n=8)$, interior workers $(n=16)$, and foragers $(n=12)$. TK expression remains stable throughout all behavioral stages. (c) Crz expression in callows $(n=8)$, interior workers $(n=16)$, and foragers $(n=12)$. Crz expression is significantly increased in foragers. For all neuropeptides, expression level of callows was set to one to determine relative changes compared with other behavioral stages. Boxes indicate 25th and 75th percentiles and the solid line represents the median of the data. Whiskers extend to all data points within 1.5 times of the interquartile length from the median. Outliers are shown as circle. For statistics, the Kruskal-Wallis test with Bonferroni correction was used. Significant different data are indicated by an asterisk $(\alpha=.05)$

integration (Heinze et al., 2018; Pfeiffer \& Homberg, 2014; Ritzmann et al., 2012; Strausfeld \& Hirth, 2013). Furthermore, the CX is involved in coordinating motor output. For example in Drosophila, short neuropeptide F (sNPF) and TK neurons in the CX were demonstrated to control locomotor activity. Moreover, TK-deficient individuals avoided central zones of an open arena supporting the hypothesis that TK is implicated in spatial orientation (Kahsai et al., 2010).

Using the three-dimensional atlas of the Cataglyphis brain as a reference (Habenstein et al., 2020), we were also able to map TK- and Ast-A-ir in less well-known CANP. In addition to the AL glomeruli and subregions of the MBs, we found TK- and Ast-A-ir in the LH, the 
VLNP, and the SIP-neuropils involved in primary and high-order olfactory processing (Galizia \& Rössler, 2010; Habenstein et al., 2020). Interestingly, treatments with Ast-A lead to dose-dependent impairments of associative olfactory learning in honeybees (Urlacher et al., 2016). Ast-A and TK might exert this function on intrinsic MB neurons (KCs) leading to effects on olfactory memory formation. Modulation at the level of the LH may provide the substrate for orchestrating the behavioral significance or sensitivity for olfactory stimuli, as it was demonstrated in fruit flies (Gui et al., 2017; Winther et al., 2006; Winther \& Ignell, 2010) and the American cockroach (Jung et al., 2013). In addition to the OL, we also found innervation by TK- and Ast-A-ir neurons of CANPs involved in processing of visual and antennal mechanosensory input. In particular, VLNP and VMNP are important target regions of visual fiber bundles from the $\mathrm{OL}$ in $C$. nodus (Habenstein et al., 2020). AMMC, VLNP, and VMNP additionally receive antennal mechanosensory projections (Grob et al., 2021) and potentially gustatory input (only AMMC) from taste hairs from the antennae, as shown in A. mellifera (Haupt, 2007). The input of visual (VMNP, VLNP), mechanosensory (VMNP, VLNP, AMMC), olfactory (VLNP), and gustatory cues (AMMC) renders these neuropils to multimodal sensory integration centers indicating that Ast-A and TK in these neuropils may exert modulatory effects on multisensory processing.

The spatial distribution of $\mathrm{Crz}$ is largely conserved in insect brains (e.g., Predel et al., 2007; Roller et al., 2003; Settembrini et al., 2011; Veenstra \& Davis, 1993; Wen \& Lee, 2008). Corazonergic cell bodies are often located in the region of the pars lateralis and exhibit projections to the SMP and the RCC. This was also found in the honeybee and termites (Verleyen et al., 2006; Závodská et al., 2009). Similarly, in C. nodus, we found a cluster of four $\mathrm{Crz}$-ir neurons with cell bodies located in the pars lateralis and projections to the SMP and the RCC. In addition, neurites extend into the FLA, a small subregion within the CANP. Whether this is also the case in other insects analyzed so far cannot be conclusively judged due to the lack of detailed brain atlases of the central protocerebral neuropils. As an important neurohemal organ, the RCC produces and releases hormones such as the adipokinetic hormone or JH (Diederen et al., 2002; Goldsworthy et al., 1972; Noriega, 2014; Tobe \& Pratt, 1974; Tobe \& Stay, 1985). JH together with the egg yolk precurser protein vitellogenin (VG) have been implicated in orchestrating the timing of behavioral transitions in social Hymenoptera (reviewed by Hamilton et al., 2017). The synthesis of JH in the corpora allata of the RCC is mediated via allatoregulatory neuropeptides from neurosecretory cells from the brain (Tobe \& Stay, 1985). Although studies in other insects could demonstrate an inhibitory effect of allatostatins and stimulatory effects of allatotropins on $\mathrm{JH}$ biosynthesis, the underlying mechanisms seem to be complex and may vary between different species (reviewed by Stay, 2000; Bendena et al., 2020). Recent studies therefore started to speculate about the participation of further neuropeptides such as sNPF or Crz in regulating $\mathrm{JH}$ biosynthesis (Bendena et al., 2020; Johnson, 2017). However, so far no evidence exists in the case of $\mathrm{Crz}$ (Johnson, 2017). Interestingly, Crz acts antagonistically to VG in Harpegnathos ants and in Drosophila (Gospocic et al., 2017). An antagonistic relationship between JH and VG was shown to be involved in behavioral maturation of honeybee workers (reviewed by Harwood et al., 2017). Crz might act on similar pathways, which makes the potential role of an interplay between $\mathrm{Crz}, \mathrm{JH}$, and VG in behavioral maturation in social insects a highly interesting target for future studies.

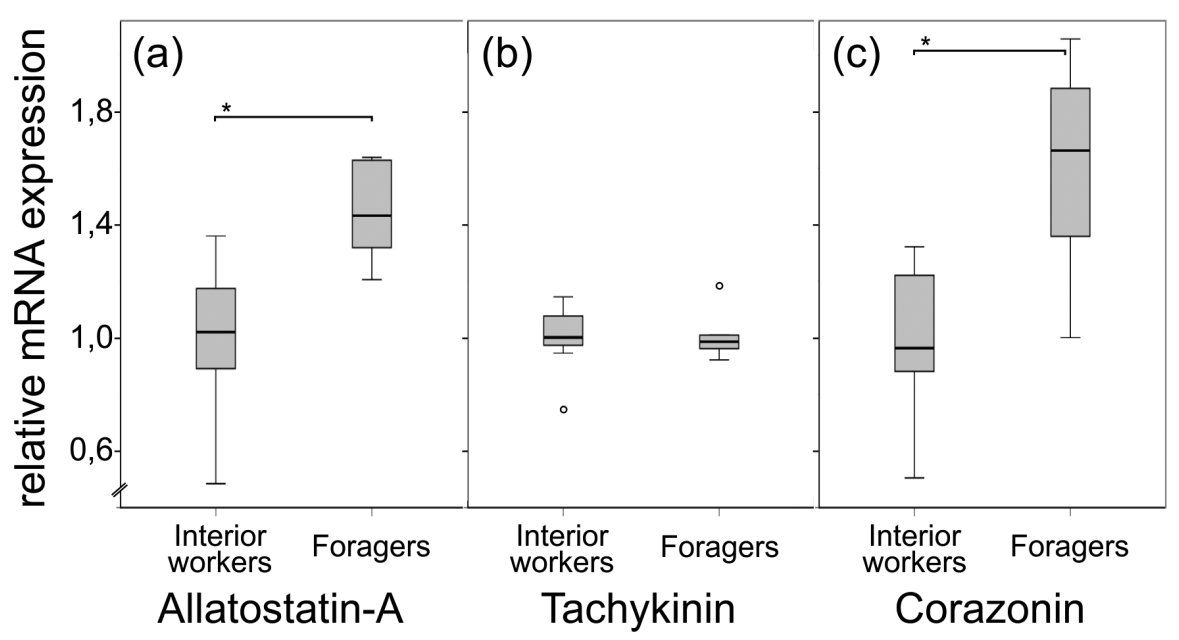

FI GURE 6 Changes of allatostatin-A (Ast-A), tachykinin (TK), and corazonin (Crz) expression in brains of interior workers and foragers (laboratory study). (a) Ast-A expression in interior workers and foragers. Ast-A expression is significantly increased in foragers. (b) TK expression in interior workers and foragers. No significant difference of the TK expression was found. (c) Crz expression in interior workers and foragers. Crz expression is significantly increased in foragers. For all neuropeptides, expression level of interior workers was set to one to determine the relative changes compared with foragers. Boxes indicate 25th and 75th percentiles and the solid line represents the median of the data. Whiskers extend to all data points within 1.5 times of the interquartile length from the median. Outliers are shown as circle. For statistics, the MannWhitney $U$ test was used. Significant different data are indicated by an asterisk $(\alpha=.05)$ 


\subsection{Changes in neuropeptide expression at different behavioral stages}

We had focused on Ast-A, TK, and Crz as candidate modulators of the behavioral transitions in Cataglyphis ants. We hypothesized if these neuropeptides act as modulators of behavioral stage transitions in adult workers, this should be reflected in changes of neuropeptide expression patterns between respective stages. In the case of Ast-A and $\mathrm{Crz}$, we found clearly increased expression levels in foragers suggesting a regulatory role associated with behavioral maturation. In contrast, TK expression levels remained unchanged in $C$. nodus brains. This is different in the honeybee, where TK brain expression is upregulated in foragers (Han et al., 2021; Takeuchi et al., 2003). Manipulation experiments further indicate that TK modulates response thresholds of the proboscis extension response (PER) in a stage specific manner: Whereas TK injection decreased PER responsiveness, TK knockdown had an opposite effect (Han et al., 2021). Injection of TK and Ast-A in another study induced aggressive behavior in 7-day-old honeybee workers (Pratavieira et al., 2018). Typically, aggressive behavior is attributed to older honeybee workers compared to younger stages (Breed et al., 1990; Pearce et al., 2001; Rittschof et al., 2018). Similar observations were made in Cataglyphis cursor (Nowbahari \& Lenoir, 1989). Schmitt et al. (2017) demonstrated slight alterations of TK innervation patterns in the CB during early stages (between Days 7 and 14) in C. fortis ants raised under controlled laboratory conditions. This may be related to an early transition between more or less motionless interior I- and highly mobile interior II stages in C. fortis (Schmid-Hempel \& Schmid-Hempel, 1984). In our present work using freshly excavated natural colonies, we were not able to differentiate between these early interior substages and rather compared the three major behavioral stages-callows, interior workers, and foragers, in which we did not find significant changes in TK expression. Similarly, the TK distribution was not different between nurse and forager honeybees (Takeuchi et al., 2004). This suggests that the changes in TK innervation of the CB observed by Schmitt et al. (2017) may reflect an age-specific transition or sensitive phase during early adult development. Future work may need to focus on potential changes of TK expression at higher temporal resolution.

The changes seen in both $\mathrm{Crz}$ expression and expansion of $\mathrm{Crz}$-ir cell body volumes suggest that this neuropeptide is a robust candidate involved in the orchestration of the interior-forager transition in Cataglyphis. In various insect species, $\mathrm{Crz}$ is associated with reproductive behavior and the control of developmental processes (e.g., Choi et al., 2005; Gospocic et al., 2017; Hou et al., 2018; Imura et al., 2020; Kim et al., 2004; Lee et al., 2008; Sugahara et al., 2018). The high concordance of findings in diverse insect taxa suggests a relatively early emergence of an ancient corazonergic pathway in the insect nervous system. Accordingly, Crz signaling could be a conserved trait that coopted the establishment of age-related polyethism in social insects, both in Hymenoptera and Isoptera (Gospocic et al., 2017). Our finding on changes in volume of $\mathrm{Crz}$-ir cell bodies together with increased expression levels in foragers further support this idea. Together with the substantial volume increase of $\mathrm{Crz}$-ir cell bodies, the expression results indicate an increase of $\mathrm{Crz}$ also at the peptide level. However, this still needs to be confirmed in future studies, for example, using quantitative mass spectrometric approaches. Our data suggest that shifts in $\mathrm{Crz}$ expression levels can be attributed to the transition from interior worker to forager (nurse-forager transition), as both the cell body volumes and mRNa expression levels do not differ between callows and interior workers. This indicates that $\mathrm{Crz}$ may potentially alter hormone release and physiological processes during the interiorforager transition, and thus might contribute substantially to the underlying behavioral switches. However, whether the increase in $\mathrm{Crz}$ expression is causal in triggering the behavioral switch or rather a consequence of changes in behavior between interior workers and foragers still requires future manipulation experiments, for example, neuropeptide injections in defined behavioral phenotypes. Although this remains speculative in Cataglyphis, a potentially important role of $\mathrm{Crz}$ in regulating behavioral transitions is supported by results from $\mathrm{Crz}$ injections inducing a forager-like behavior in the ponerine (basal) ant species H. saltator (Gospocic et al., 2017). However, due to the large phylogenetic distance between the two ant species future manipulation in Cataglyphis are necessary to confirm this.

Leaving the social environment and darkness of the nest for the first time is probably the most far-reaching behavioral decision in the life of social insects. Accordingly, the correct timing of this transition is most important for the ecological success of a colony. Furthermore, the transition needs to be flexible and adjustable to the specific needs of a colony. This requires the control of a variety of external and intrinsic feedback mechanisms. $\mathrm{Crz}$ appears to be one of the key players in these complex species-specific systems, which is most likely orchestrated by further neuropeptide modulators, hormones, and biogenic amines.

\section{5 | CONCLUSION}

This study revealed the distribution of the neuropeptides Ast-A, Crz, and TK in major neuropils and less-well known central neuropils of the brain in $C$. nodus worker ants. Although differences are present between the distribution of Ast-A- and TK-ir, their wide distribution in major sensory neuropils and high-order integration centers suggests potential roles in modulating a diverse range of behavioral processes. Both Ast-A and $\mathrm{Crz}$ expression levels increase at the interior-forager transition, whereas TK expression levels remain unchanged. This correlates with a volumetric increase of $\mathrm{Crz}$-ir cell bodies indicating a related increase in the amounts of neuropeptide. Both correlations are suggestive of a role of $\mathrm{Crz}$ - and Ast-A in age-related polyethism in Cataglyphis ants. In the light of these results, future experimental manipulations of $\mathrm{Crz}$ - and Ast-A levels are highly promising in revealing the specific function and causal role of these neuropeptides in modulating behavioral transitions of the ants.

\section{ACKNOWLEDGMENTS}

The authors thank the Greek government and the management board of the Strofylia National Park for the permission to perform their research in the park and to transfer Cataglyphis ants to Germany. The 
authors are very grateful for the administrative help from Vasiliki Orfanou, Georgia Karamperou, and Christos Georgiadis and their support during their fieldwork. The authors especially thank all field assistants in the years 2018 and 2019-the study would not have been possible without arduous work even in extreme heat or during nest excavations throughout the night. The authors also thank Yasemin Brückner and Clara Tritscher for the reconstruction of neurons in Amira. Special thanks go to Kornelia Grübel (University of Würzburg) for her support with confocal-image acquisition and Susanne Neupert for suggesting volume measurements on $\mathrm{Crz}$-ir cell bodies. The authors further thank E. Buchner and C. Wegener for providing the synapsin antibody, J. A. Veenstra for the kind gift of the $\mathrm{Crz}$ antisera, and D. Nässel for kindly providing them with TK and Ast-A antibodies. This study was supported by the German Research Foundation (DFG), DFG Ro1177/7-1 and DFG equipment grant INST 93/829-1, both to W. R. Open Access funding enabled and organized by Projekt DEAL.

\section{CONFLICT OF INTEREST}

The authors declare no conflicts of interest.

\section{AUTHOR CONTRIBUTIONS}

Wolfgang Rössler, Jens Habenstein, and Markus Thamm: Contributed to study concept and design. Jens Habenstein: Performed the preparations and acquisition of data. Jens Habenstein: Wrote the first draft of the manuscript. Wolfgang Rössler and Markus Thamm: Critically reviewed and edited the manuscript. Wolfgang Rössler: Obtained funding. All authors contributed to data analyses and interpretations and approved the final version of the manuscript.

\section{PEER REVIEW}

The peer review history for this article is available at https://publons. com/publon/10.1002/cne.25166.

\section{DATA AVAILABILITY STATEMENT}

The data that support the findings of this study are available from the authors upon reasonable request.

\section{ORCID}

Jens Habenstein (D) https://orcid.org/0000-0003-3589-6436 Markus Thamm (D) https://orcid.org/0000-0003-0480-2206 Wolfgang Rössler (iD https://orcid.org/0000-0002-5195-8214

\section{REFERENCES}

Andreatta, G., Broyart, C., Borghgraef, C., Vadiwala, K., Kozin, V., Polo, A., Bileck, A., Beets, I., Schoofs, L., Gerner, C., \& Raible, F. (2020). Corazonin signaling integrates energy homeostasis and lunar phase to regulate aspects of growth and sexual maturation in Platynereis. Proceedings of the National Academy of Sciences of the United States of America, 117(2), 1097-1106.

Bendena, W. G., Hui, J. H., Chin-Sang, I., \& Tobe, S. S. (2020). Neuropeptide and microRNA regulators of juvenile hormone production. General and Comparative Endocrinology, 295, 113507.

Breed, M. D., Robinson, G. E., \& Page, R. E. (1990). Division of labor during honey bee colony defense. Behavioral Ecology and Sociobiology, 27(6), 395-401.
Buehlmann, C., Graham, P., Hansson, B. S., \& Knaden, M. (2014). Desert ants locate food by combining high sensitivity to food odors with extensive crosswind runs. Current Biology, 24(9), 960-964.

Carlsson, M. A., Schäpers, A., Nässel, D. R., \& Janz, N. (2013). Organization of the olfactory system of Nymphalidae butterflies. Chemical senses, 38(4), 355-367.

Choi, Y. J., Lee, G., Hall, J. C., \& Park, J. H. (2005). Comparative analysis of Corazonin-encoding genes ( $\mathrm{Crz}$ 's) in Drosophila species and functional insights into Crz-expressing neurons. Journal of Comparative Neurology, 482(4), 372-385.

Diederen, J. H., Oudejans, R. C., Harthoorn, L. F., \& van der Horst, D. J. (2002). Cell biology of the adipokinetic hormone-producing neurosecretory cells in the locust corpus cardiacum. Microscopy Research and Technique, 56(3), 227-236.

el Jundi, B., Pfeiffer, K., Heinze, S., \& Homberg, U. (2014). Integration of polarization and chromatic cues in the insect sky compass. Journal of Comparative Physiology A, 200(6), 575-589.

Fleischmann, P. N., Grob, R., Müller, V. L., Wehner, R., \& Rössler, W. (2018). The geomagnetic field is a compass cue in Cataglyphis ant navigation. Current Biology, 28(9), 1440-44. e2.

Fleischmann, P. N., Grob, R., Wehner, R., \& Rössler, W. (2017). Speciesspecific differences in the fine structure of learning walk elements in Cataglyphis ants. Journal of Experimental Biology, 220(13), 2426-2435.

Fricker, L. D. (2012). Neuropeptides and other bioactive peptides: From discovery to function. In Colloquium series on neuropeptides (pp. 1-122). Morgan \& Claypool Life Sciences.

Gade, G., Hoffmann, K.-H., \& Spring, J. H. (1997). Hormonal regulation in insects: Facts, gaps, and future directions. Physiological Reviews, 77(4), 963-1032.

Galizia, C. G., \& Rössler, W. (2010). Parallel olfactory systems in insects: Anatomy and function. Annual Review of Entomology, 55, 399-420.

Godenschwege, T. A., Reisch, D., Diegelmann, S., Eberle, K., Funk, N., Heisenberg, M., Hoppe, V., Hoppe, J., Klagges, B. R. E., Martin, J. R., Nikitina, E. A., Putz, G., Reifegerste, R., Reisch, N., Rister, J., Schaupp, M., Scholz, H., Schwarzel, M., Werner, U., ... Buchner, E. (2004). Flies lacking all synapsins are unexpectedly healthy but are impaired in complex behaviour. European Journal of Neuroscience, 20 (3), 611-622

Goldsworthy, G., Johnson, R., \& Mordue, W. (1972). In vivo studies on the release of hormones from the corpora cardiaca of locusts. Journal of Comparative Physiology, 79(1), 85-96.

Gospocic, J., Shields, E. J., Glastad, K. M., Lin, Y., Penick, C. A., Yan, H., Mikheyev, A., Linksvayer, T., Garcia, B., Berger, S., Liebig, J., Reinberg, D., \& Bonasio, R. (2017). The neuropeptide corazonin controls social behavior and caste identity in ants. Cell, 170(4), 748-759.

Grob, R., Fleischmann, P. N., Grübel, K., Wehner, R., \& Rössler, W. (2017). The role of celestial compass information in Cataglyphis ants during learning walks and for neuroplasticity in the central complex and mushroom bodies. Frontiers in Behavioral Neuroscience, 11, 226.

Grob, R., Fleischmann, P. N., \& Rössler, W. (2019). Learning to navigate-How desert ants calibrate their compass systems. e-Neuroforum, 25(2), 109-120.

Grob, R., Tritscher, C., Grübel, K., Stigloher, C., Groh, C., Fleischmann, P. N., et al. (2021). Johnston's organ and its central projections in Cataglyphis desert ants. Journal of Comparative Neurology, 529(8), 2138-2155.

Groh, C., \& Rössler, W. (2011). Comparison of microglomerular structures in the mushroom body calyx of neopteran insects. Arthropod Structure \& Development, 40(4), 358-367.

Grünewald, B. (1999). Physiological properties and response modulations of mushroom body feedback neurons during olfactory learning in the honeybee, Apis mellifera. Journal of Comparative Physiology A, 185(6), 565-576.

Gui, S.-H., Jiang, H.-B., Xu, L., Pei, Y.-X., Liu, X.-Q., Smagghe, G., \& Wang, J. J. (2017). Role of a tachykinin-related peptide and its receptor in modulating the olfactory sensitivity in the oriental fruit fly, 
Bactrocera dorsalis (Hendel). Insect Biochemistry and Molecular Biology, 80, 71-78.

Habenstein, J., Amini, E., Grübel, K., el Jundi, B., \& Rössler, W. (2020). The brain of Cataglyphis ants: Neuronal organization and visual projections. Journal of Comparative Neurology, 528(18), 3479-3506.

Habenstein, J., Schmitt, F., Liessem, S., Ly, A., Trede, D., Wegener, C., Predel, R., Rössler, W., \& Neupert, S. (2021). Transcriptomic, peptidomic and mass spectrometry imaging analysis of the brain in the ant Cataglyphis nodus. Journal of Neurochemistry.

Haehnel, M., \& Menzel, R. (2010). Sensory representation and learningrelated plasticity in mushroom body extrinsic feedback neurons of the protocerebral tract. Frontiers in Systems Neuroscience, 4, 161.

Hamilton, A., Shpigler, H., Bloch, G., Wheeler, D. E., \& Robinson, G. E. (2017). Endocrine influences on insect societies. Hormones, Brain, and Behavior, 421-451.

Han, B., Wei, Q., Wu, F., Hu, H., Ma, C., Meng, L., et al. (2021). Neuromodulation of behavioral specialization: Tachykinin signaling inhibits task-specific behavioral responsiveness in honeybee workers. elife, 10, e64830.

Hansen, I., Sehnal, F., Meyer, S., \& Scheller, K. (2001). Corazonin gene expression in the waxmoth Galleria mellonella. Insect Molecular Biology, 10(4), 341-346.

Harwood, G. P., Ihle, K. E., Salmela, H., \& Amdam, G. (2017). Regulation of honeybee worker (Apis mellifera) life histories by vitellogenin. Hormones, Brain, and Behavior, 403-420.

Haupt, S. S. (2007). Central gustatory projections and side-specificity of operant antennal muscle conditioning in the honeybee. Journal of Comparative Physiology A, 193(5), 523-535.

Heinze, S., Narendra, A., \& Cheung, A. (2018). Principles of insect path integration. Current Biology, 28(17), R1043-R1058.

Heinze, S., \& Reppert, S. M. (2012). Anatomical basis of sun compass navigation I: The general layout of the monarch butterfly brain. Journal of Comparative Neurology, 520(8), 1599-1628.

Hofbauer, A., Ebel, T., Waltenspiel, B., Oswald, P., Chen, Y.-C., Halder, P., et al. (2009). The Wuerzburg hybridoma library against Drosophila brain. Journal of Neurogenetics, 23(1-2), 78-91.

Hölldobler, B., \& Wilson, E. O. (1990). The ants. Harvard University Press.

Homberg, U., Heinze, S., Pfeiffer, K., Kinoshita, M., \& el Jundi, B. (2011). Central neural coding of sky polarization in insects. Philosophical Transactions of the Royal Society B: Biological Sciences, 366(1565), 680-687.

Hou, Q.-L., Chen, E.-H., Jiang, H.-B., Yu, S.-F., Yang, P.-J., Liu, X.-Q., Park, Y., Wang, J. J., \& Smagghe, G. (2018). Corazonin signaling is required in the male for sperm transfer in the oriental fruit fly Bactrocera dorsalis. Frontiers in Physiology, 9, 660.

Hou, Q.-L., Jiang, H.-B., Gui, S.-H., Chen, E.-H., Wei, D.-D., Li, H.-M., et al. (2017). A role of corazonin receptor in larval-pupal transition and pupariation in the oriental fruit fly Bactrocera dorsalis (Hendel) (Diptera: Tephritidae). Frontiers in Physiology, 8, 77.

Huber, R., \& Knaden, M. (2015). Egocentric and geocentric navigation during extremely long foraging paths of desert ants. Journal of Comparative Physiology A, 201(6), 609-616.

Hughes, W. O., Sumner, S., van Borm, S., \& Boomsma, J. J. (2003). Worker caste polymorphism has a genetic basis in Acromyrmex leaf-cutting ants. Proceedings of the National Academy of Sciences of the United States of America, 100(16), 9394-9397.

Im, S. H., Takle, K., Jo, J., Babcock, D. T., Ma, Z., Xiang, Y., \& Galko, M. J. (2015). Tachykinin acts upstream of autocrine hedgehog signaling during nociceptive sensitization in Drosophila. eLife, 4, e10735.

Immonen, E. V., Dacke, M., Heinze, S., \& el Jundi, B. (2017). Anatomical organization of the brain of a diurnal and a nocturnal dung beetle. Journal of Comparative Neurology, 525(8), 1879-1908.

Imura, E., Shimada-Niwa, Y., Nishimura, T., Hückesfeld, S., Schlegel, P., Ohhara, Y., et al. (2020). The Corazonin-PTTH neuronal axis controls systemic body growth by regulating basal ecdysteroid biosynthesis in Drosophila melanogaster. Current Biology, 30(11), 2156-65. e5.
Ito, K., Shinomiya, K., Ito, M., Armstrong, J. D., Boyan, G., Hartenstein, V., Harzsch, S., Heisenberg, M., Homberg, U., Jenett, A., Keshishian, H., Restifo, L. L., Rössler, W., Simpson, J. H., Strausfeld, N. J., Strauss, R., Vosshall, L. B., \& Insect Brain Name Working Group. (2014). A systematic nomenclature for the insect brain. Neuron, 81(4), 755-765.

Johnson, E. C. (2017). Stressed out insects II. Physiology, behavior, and neuroendocrine circuits mediating stress responses. Hormones, Brain, and Behavior, 465-481.

Jung, J. W., Kim, J.-H., Pfeiffer, R., Ahn, Y.-J., Page, T. L., \& Kwon, H. W. (2013). Neuromodulation of olfactory sensitivity in the peripheral olfactory organs of the American cockroach, Periplaneta americana. PLoS One, 8(11), e81361.

Kahsai, L., Martin, J. R., \& Winther, A. M. (2010). Neuropeptides in the Drosophila central complex in modulation of locomotor behavior. Journal of Experimental Biology, 213(Pt 13), 2256-2265.

Kahsai, L., \& Winther, A.. M. (2011). Chemical neuroanatomy of the Drosophila central complex: Distribution of multiple neuropeptides in relation to neurotransmitters. Journal of Comparative Neurology, 519(2), 290-315.

Kapan, N., Lushchak, V., Luo, J., \& Nässel, D. R. (2012). Identified peptidergic neurons in the Drosophila brain regulate insulin-producing cells, stress responses and metabolism by coexpressed short neuropeptide F and corazonin. Cellular and Molecular Life Sciences, 69(23), 4051-4066.

Kastin, A. (2013). Handbook of biologically active peptides. Academic Press.

Kim, Y.-J., Spalovská-Valachová, I., Cho, K.-H., Zitnanova, I., Park, Y., Adams, M. E., et al. (2004). Corazonin receptor signaling in ecdysis initiation. Proceedings of the National Academy of Sciences of the United States of America, 101(17), 6704-6709.

Klagges, B. R., Heimbeck, G., Godenschwege, T. A., Hofbauer, A., Pflugfelder, G. O., Reifegerste, R., et al. (1996). Invertebrate synapsins: A single gene codes for several isoforms in Drosophila. Journal of Neuroscience, 16(10), 3154-3165.

Ko, K. I., Root, C. M., Lindsay, S. A., Zaninovich, O. A., Shepherd, A. K., Wasserman, S. A., Kim, S. M., \& Wang, J. W. (2015). Starvation promotes concerted modulation of appetitive olfactory behavior via parallel neuromodulatory circuits. eLife, 4, e08298.

Kreissl, S., Strasser, C., \& Galizia, C. G. (2010). Allatostatin immunoreactivity in the honeybee brain. Journal of Comparative Neurology, 518(9), 1391-1417.

Kubrak, O. I., Lushchak, O. V., Zandawala, M., \& Nässel, D. R. (2016). Systemic corazonin signalling modulates stress responses and metabolism in Drosophila. Open Biology, 6(11), 160152.

Lee, G., Kim, K.-M., Kikuno, K., Wang, Z., Choi, Y.-J., \& Park, J. H. (2008). Developmental regulation and functions of the expression of the neuropeptide corazonin in Drosophila melanogaster. Cell and Tissue Research, 331(3), 659-673.

Lourenço, A. P., Mackert, A., dos Santos, C. A., \& Simões, Z. L. P. (2008). Validation of reference genes for gene expression studies in the honey bee, Apis mellifera, by quantitative real-time RT-PCR. Apidologie, 39(3), 372-385.

Maeno, K., Gotoh, T., \& Tanaka, S. (2004). Phase-related morphological changes induced by [His7]-corazonin in two species of locusts, Schistocerca gregaria and Locusta migratoria (Orthoptera: Acrididae). Bulletin of Entomological Research, 94(4), 349-357.

Moreira, A. C., dos Santos, A. M., Carneiro, R. L., Bueno, O. C., \& Souza, D. H. F. (2017). Validation of reference genes in leaf-cutting ant Atta sexdens rubropilosa in different developmental stages and tissues. International Journal of Environment, Agriculture and Biotechnology, 2(2), 238725.

Nässel, D. R., \& Zandawala, M. (2019). Recent advances in neuropeptide signaling in Drosophila, from genes to physiology and behavior. Progress in Neurobiology, 179, 101607.

Neupert, S., Fusca, D., Schachtner, J., Kloppenburg, P., \& Predel, R. (2012). Toward a single-cell-based analysis of neuropeptide expression in Periplaneta americana antennal lobe neurons. Journal of Comparative Neurology, 520(4), 694-716. 
Noriega, F. G. (2014). Juvenile hormone biosynthesis in insects: What is new, what do we know, and what questions remain? International Scholarly Research Notices, 2014, 1-16.

Nowbahari, E., \& Lenoir, A. (1989). Age-related changes in aggression in ant Cataglyphis cursor (Hymenoptera, Formicidae): Influence on intercolonial relationships. Behavioural Processes, 18(1-3), 173-181.

Pasch, E., Muenz, T. S., \& Rössler, W. (2011). CaMKII is differentially localized in synaptic regions of Kenyon cells within the mushroom bodies of the honeybee brain. Journal of Comparative Neurology, 519(18), 3700-3712.

Pearce, A., Huang, Z., \& Breed, M. (2001). Juvenile hormone and aggression in honey bees. Journal of Insect Physiology, 47(11), 1243-1247.

Pfeiffer, K., \& Homberg, U. (2014). Organization and functional roles of the central complex in the insect brain. Annual Review of Entomology, 59, 165-184.

Pratavieira, M., da Silva Menegasso, A. R., Garcia, A. M., dos Santos, D. S., Gomes, P. C., Malaspina, O., et al. (2014). MALDI imaging analysis of neuropeptides in the Africanized honeybee (Apis mellifera) brain: Effect of ontogeny. Journal of Proteome Research, 13(6), 3054-3064.

Pratavieira, M., Menegasso, A. R. D. S., Esteves, F. G., Sato, K. U., Malaspina, O., \& Palma, M. S. (2018). MALDI imaging analysis of neuropeptides in africanized honeybee (Apis mellifera) brain: Effect of aggressiveness. Journal of Proteome Research, 17(7), 2358-2369.

Predel, R. (2001). Peptidergic neurohemal system of an insect: Mass spectrometric morphology. Journal of Comparative Neurology, 436(3), 363-375.

Predel, R., Neupert, S., Russell, W. K., Scheibner, O., \& Nachman, R. J. (2007). Corazonin in insects. Peptides, 28(1), 3-10.

Raabe, M. (2012). Recent developments in insect neurohormones. Springer Science \& Business Media.

Ratzka, C., Liang, C., Dandekar, T., Gross, R., \& Feldhaar, H. (2011). Immune response of the ant Camponotus floridanus against pathogens and its obligate mutualistic endosymbiont. Insect Biochemistry and Molecular Biology, 41(8), 529-536.

Reim, T., Thamm, M., Rolke, D., Blenau, W., \& Scheiner, R. (2013). Suitability of three common reference genes for quantitative real-time PCR in honey bees. Apidologie, 44(3), 342-350.

Rittschof, C. C., Vekaria, H. J., Palmer, J. H., \& Sullivan, P. G. (2018). Brain mitochondrial bioenergetics change with rapid and prolonged shifts in aggression in the honey bee, Apis mellifera. Journal of Experimental Biology, 221(8), jeb176917.

Ritzmann, R. E., Harley, C. M., Daltorio, K. A., Tietz, B. R., Pollack, A. J., Bender, J. A., et al. (2012). Deciding which way to go: How do insects alter movements to negotiate barriers? Frontiers in Neuroscience, 6, 97.

Robinson, G. E. (1992). Regulation of division of labor in insect societies. Annual Review of Entomology, 37, 637-665.

Robinson, G. E. (2002). Genomics and integrative analyses of division of labor in honeybee colonies. The American Naturalist, 160(S6), S160-S172.

Roller, L., Tanaka, Y., \& Tanaka, S. (2003). Corazonin and corazonin-like substances in the central nervous system of the Pterygote and Apterygote insects. Cell and Tissue Research, 312(3), 393-406.

Ronacher, B. (2008). Path integration as the basic navigation mechanism of the desert ant Cataglyphis fortis (Forel, 1902) (Hymenoptera: Formicidae). Myrmecological News, 11, 53-62.

Rössler, W. (2019). Neuroplasticity in desert ants (Hymenoptera: Formicidae)-importance for the ontogeny of navigation. Myrmecological News, 29, 1-20.

Schmid-Hempel, P., \& Schmid-Hempel, R. (1984). Life duration and turnover of foragers in the ant Cataglyphis bicolor (Hymenoptera, Formicidae). Insectes Sociaux, 31(4), 345-360.

Schmitt, F., Stieb, S. M., Wehner, R., \& Rössler, W. (2016). Experiencerelated reorganization of giant synapses in the lateral complex: Potential role in plasticity of the sky-compass pathway in the desert ant Cataglyphis fortis. Developmental Neurobiology, 76(4), 390-404.
Schmitt, F., Vanselow, J. T., Schlosser, A., Wegener, C., \& Rossler, W. (2017). Neuropeptides in the desert ant Cataglyphis fortis: Mass spectrometric analysis, localization, and age-related changes. Journal of Comparative Neurology, 525(4), 901-918.

Settembrini, B. P., de Pasquale, D., Postal, M., Pinto, P. M., Carlini, C. R., \& Villar, M. J. (2011). Distribution and characterization of Corazonin in the central nervous system of Triatoma infestans (Insecta: Heteroptera). Peptides, 32(3), 461-468.

Siegmund, T., \& Korge, G. (2001). Innervation of the ring gland of Drosophila melanogaster. Journal of Comparative Neurology, 431(4), 481-491.

Siju, K., Reifenrath, A., Scheiblich, H., Neupert, S., Predel, R., Hansson, B. S., et al. (2014). Neuropeptides in the antennal lobe of the yellow fever mosquito, Aedes aegypti. Journal of Comparative Neurology, 522(3), 592-608.

Stay, B. (2000). A review of the role of neurosecretion in the control of juvenile hormone synthesis: A tribute to Berta Scharrer. Insect Biochemistry and Molecular Biology, 30(8-9), 653-662.

Stieb, S. M., Hellwig, A., Wehner, R., \& Rössler, W. (2012). Visual experience affects both behavioral and neuronal aspects in the individual life history of the desert ant Cataglyphis fortis. Developmental Neurobiology, 72(5), 729-742.

Stieb, S. M., Muenz, T. S., Wehner, R., \& Rossler, W. (2010 May). Visual experience and age affect synaptic organization in the mushroom bodies of the desert ant Cataglyphis fortis. Developmental Neurobiology, 70 (6), 408-423.

Strausfeld, N. J. (2002). Organization of the honey bee mushroom body: Representation of the calyx within the vertical and gamma lobes. Journal of Comparative Neurology, 450(1), 4-33.

Strausfeld, N. J., \& Hirth, F. (2013). Deep homology of arthropod central complex and vertebrate basal ganglia. Science, 340(6129), 157-161.

Sugahara, R., Tanaka, S., Jouraku, A., \& Shiotsuki, T. (2018). Identification of a transcription factor that functions downstream of corazonin in the control of desert locust gregarious body coloration. Insect Biochemistry and Molecular Biology, 97, 10-18.

Takeuchi, H., Yasuda, A., Yasuda-Kamatani, Y., Kubo, T., \& Nakajima, T. (2003). Identification of a tachykinin-related neuropeptide from the honeybee brain using direct MALDI-TOF MS and its gene expression in worker, queen and drone heads. Insect Molecular Biology, 12(3), 291-298.

Takeuchi, H., Yasuda, A., Yasuda-Kamatani, Y., Sawata, M., Matsuo, Y., Kato, A., Tsujimoto, A., Nakajima, T., \& Kubo, T. (2004). Preprotachykinin gene expression in the brain of the honeybee Apis mellifera. Cell and Tissue Research, 316(2), 281-293.

Tanaka, S., Zhu, D.-H., Hoste, B., \& Breuer, M. (2002). The dark-color inducing neuropeptide,[His7]-corazonin, causes a shift in morphometic characteristics towards the gregarious phase in isolated-reared (solitarious) Locusta migratoria. Journal of Insect Physiology, 48(11), 1065-1074.

Tanaka, Y., Hua, Y.-J., Roller, L., \& Tanaka, S. (2002). Corazonin reduces the spinning rate in the silkworm, Bombyx mori. Journal of Insect Physiology, 48(7), 707-714.

Tawfik, A. I., Tanaka, S., de Loof, A., Schoofs, L., Baggerman, G., Waelkens, E., et al. (1999). Identification of the gregarizationassociated dark-pigmentotropin in locusts through an albino mutant. Proceedings of the National Academy of Sciences of the United States of America, 96(12), 7083-7087.

Tobe, S. S., \& Pratt, G. E. (1974). The influence of substrate concentrations on the rate of insect juvenile hormone biosynthesis by corpora allata of the desert locust in vitro. Biochemical Journal, 144(1), 107-113.

Tobe, S. S., \& Stay, B. (1985). Structure and regulation of the corpus allatum. Advances in Insect Physiology, 18, 305-432.

Urlacher, E., Devaud, J.-M., \& Mercer, A. R. (2019). Changes in responsiveness to allatostatin treatment accompany shifts in stress reactivity in young worker honey bees. Journal of Comparative Physiology A, 205(1), $51-59$. 
Urlacher, E., Soustelle, L., Parmentier, M. L., Verlinden, H., Gherardi, M. J., Fourmy, D., Mercer, A. R., Devaud, J. M., \& Massou, I. (2016). Honey bee allatostatins target galanin/somatostatin-like receptors and modulate learning: A conserved function? PLoS One, 11(1), e0146248.

Veelaert, D., Schoofs, L., \& de Loof, A. (1998). Peptidergic control of the corpus cardiacum-corpora allata complex of locusts. In International review of cytology (pp. 249-302). Elsevier.

Veenstra, J. A. (1991). Presence of corazonin in three insect species, and isolation and identification of [His7] corazonin from Schistocerca americana. Peptides, 12(6), 1285-1289.

Veenstra, J. A., \& Davis, N. T. (1993). Localization of corazonin in the nervous system of the cockroach Periplaneta americana. Cell and Tissue Research, 274(1), 57-64.

Verleyen, P., Baggerman, G., Mertens, I., Vandersmissen, T., Huybrechts, J., van Lommel, A., et al. (2006). Cloning and characterization of a third isoform of corazonin in the honey bee Apis mellifera. Peptides, 27(3), 493-499.

Verlinden, H., Gijbels, M., Lismont, E., Lenaerts, C., Broeck, J. V., \& Marchal, E. (2015). The pleiotropic allatoregulatory neuropeptides and their receptors: A mini-review. Journal of Insect Physiology, 80, 2-14.

Vitzthum, H., Homberg, U., \& Agricola, H. (1996). Distribution of dipallatostatin I-like immunoreactivity in the brain of the locust Schistocerca gregaria with detailed analysis of immunostaining in the central complex. Journal of Comparative Neurology, 369(3), 419-437.

von Hadeln, J., Althaus, V., Häger, L., \& Homberg, U. (2018). Anatomical organization of the cerebrum of the desert locust Schistocerca gregaria. Cell and Tissue Research, 374(1), 39-62.

Weaver, R., \& Audsley, N. (2009). Neuropeptide regulators of juvenile hormone synthesis: Structures, functions, distribution, and unanswered questions. Annals of the New York Academy of Sciences, 1163(1), 316-329.

Wehner, R., \& Rössler, W. (2013). Bounded plasticity in the desert ant's navigational tool kit. In Handbook of Behavioral Neuroscience (pp. 514-529). Elsevier.

Wen, C. J., \& Lee, H. J. (2008). Mapping the cellular network of the circadian clock in two cockroach species. Archives of Insect Biochemistry and Physiology, 68(4), 215-231.
Wilson, E. O. (1971). The insect societies. Belknap Press.

Wilson, E. O. (1980). Caste and division of labor in leaf-cutter ants (Hymenoptera: Formicidae: Atta). Behavioral Ecology and Sociobiology, 7(2), 157-165.

Wilson, E. O. (1984). The relation between caste ratios and division of labor in the ant genus Pheidole (Hymenoptera: Formicidae). Behavioral Ecology and Sociobiology, 16(1), 89-98.

Winther, A., \& Nässel, D. (2001). Intestinal peptides as circulating hormones: Release of tachykinin-related peptide from the locust and cockroach midgut. Journal of Experimental Biology, 204(7), 1269-1280.

Winther, Å. M., Acebes, A., \& Ferrús, A. (2006). Tachykinin-related peptides modulate odor perception and locomotor activity in Drosophila. Molecular and Cellular Neuroscience, 31(3), 399-406.

Winther, A.. M., \& Ignell, R. (2010). Local peptidergic signaling in the antennal lobe shapes olfactory behavior. Fly, 4(2), 167-171.

Winther, Å. M., Siviter, R. J., Isaac, R. E., Predel, R., \& Nässel, D. R. (2003). Neuronal expression of tachykinin-related peptides and gene transcript during postembryonic development of Drosophila. Journal of Comparative Neurology, 464(2), 180-196.

Zandawala, M., Nguyen, T., Balanyà Segura, M., Johard, H. A., Amcoff, M., Wegener, C., et al. (2021). A neuroendocrine pathway modulating osmotic stress in Drosophila. PLoS Genetics, 17(3), e1009425.

Závodská, R., Wen, C.-J., Sehnal, F., Hrdý, I., Lee, H.-J., \& Sauman, I. (2009). Corazonin-and PDF-immunoreactivities in the cephalic ganglia of termites. Journal of Insect Physiology, 55(5), 441-449.

How to cite this article: Habenstein, J., Thamm, M., \& Rössler, W. (2021). Neuropeptides as potential modulators of behavioral transitions in the ant Cataglyphis nodus. Journal of Comparative Neurology, 529(12), 3155-3170. https://doi.org/ 10.1002/cne.25166 